\title{
Flow Injection Analysis in Industrial Biotechnology
}

\author{
Hansen, Elo Harald; Miró, Manuel
}

Published in:

Wiley Encyclopedia of Industrial Biotechnology:

Publication date:

2009

Document Version

Early version, also known as pre-print

Link back to DTU Orbit

Citation (APA):

Hansen, E. H., \& Miró, M. (2009). Flow Injection Analysis in Industrial Biotechnology. In Wiley Encyclopedia of Industrial Biotechnology: Bioprocess, bioseparation, and cell technology John Wiley \& Sons Ltd.

\section{General rights}

Copyright and moral rights for the publications made accessible in the public portal are retained by the authors and/or other copyright owners and it is a condition of accessing publications that users recognise and abide by the legal requirements associated with these rights.

- Users may download and print one copy of any publication from the public portal for the purpose of private study or research.

- You may not further distribute the material or use it for any profit-making activity or commercial gain

- You may freely distribute the URL identifying the publication in the public portal

If you believe that this document breaches copyright please contact us providing details, and we will remove access to the work immediately and investigate your claim. 


\title{
FLOW INJECTION ANALYSIS IN INDUSTRIAL BIOTECHNOLOGY
}

\author{
Elo Harald Hansen ${ }^{\mathrm{a}^{*}}$ and Manuel Miró ${ }^{\mathrm{b}}$
}

a) Department of Chemistry, Technical University of Denmark, Kemitorvet, Building 207, DK-2800 Kgs. Lyngby, Denmark

b) Department of Chemistry, Faculty of Sciences, University of the Balearic Islands, Carretera de Valldemossa, km. 7.5, E-07122-Palma de Mallorca, Illes Balears, Spain.

\begin{abstract}
Flow injection analysis (FIA) is an analytical chemical continuous-flow (CF) method which in contrast to traditional CF-procedures does not rely on complete physical mixing (homogenisation) of the sample and the reagent(s) or on attaining chemical equilibria of the chemical reactions involved. Exploiting controllable dispersion of the injected sample within the reagent-containing carrier stream and strictly reproducible timing of all events taking place, it is based on measuring transient signals, which not only implies very high sampling rates, but also, and most importantly, permits implementation of a number of novel methodologies which are not feasible when performed under batch conditions or by conventional CF-procedures. Demonstrated for selected bioanalytical and technological applications encompassing cellular and enzymatic assays as well as monitoring of culture media, the principles and operational characteristics of FIA are first outlined, and then its downscaled/miniaturized sequels, that is, sequential injection analysis (SIA) and lab-onvalve (LOV), are detailed. Thus, in SIA the sample and reagents are, via the use of a multiposition valve and an attached syringe pump operated under full programmable control, aspirated sequentially and then propelled forward allowing the sample and reagent(s) to be intermixed and, if called for, subjected to appropriate treatments before analyte detection. This infers that merely minute sample/reagents volumes are consumed, hence leading to generation of small amounts of waste. In LOV this downscaling is taken further by using a small monolithic structure within which all sample manipulations and ultimate analyte detection under programmable control can be effected. Even bead-materials with different surface groups/characteristics, including live cells, can be handled and utilized as demonstrated. Because the syringe pump in SIA and LOV can be used for accurately aspirating, propelling or even stopping the flow, these modi operandi allow fully to exploit the interplay between the kinetics and the thermodynamics of the chemical reactions involved, so that there are no restrictions whatsoever as to the chemistries that can be implemented, even if they entail multi-step reactions. Representative bioanalytical examples of this interplay are presented.
\end{abstract}

Key Words: Flow injection (FI); Sequential injection (SI); Lab-on-valve (LOV); Process control; Bioassays; culture media; enzyme; kinetics; thermodynamics.

\section{X.1 Introduction}

Introduced in 1975, flow injection analysis (FIA) was an entirely new approach to perform chemical analysis (1). While such assays for centuries had been based on thorough mixing of sample with appropriate reagent(s), and waiting for chemical equilibrium to be obtained (that is, both physical and chemical homogenization), FIA was, as illustrated in Fig. 1(a), founded on injection of a well defined volume of sample into an inert or reagent-containing carrier stream, to which additional reagents, if called for, could be added downstream, thereby accomplishing partial 
mixing of the components to promote chemical reaction, the result of which subsequently could be monitored by a suitable flow-though cell, which may continuously observe an absorbance, an electrode potential, or any other physical parameter as it changes on passage of the sample material through the flow cell. Thus, the physical and chemical homogenization, which, in fact, had been the key stones in batch assays and also in the then existing (predominantly clinical) automated analysers, were not any more necessary, which, in turn, opened up entirely new avenues to perform chemical assays, where non-steady state conditions could be exploited. The ensuing years have amply proven these advantages, as clearly evidenced in the large number of FIA publications which have been published, counting at the beginning of 2008 altogether more than 17.500, to which should be added ca. 20 dedicated monographs and hundreds of Ph.D.-theses (2).

During its existence, FIA has undergone certain changes and modifications, i.e., it was in 1990 supplemented by Sequential Injection Analysis (SIA), also termed the $2^{\text {nd }}$ generation of FIA $(3,4)$, and in 2000 by the Lab-on-Valve (LOV), the $3^{\text {rd }}$ generation of FIA (5). Thus, the present chapter will focus on these three generations of FIA, their characteristics and their applications, that is, initially outlining the distinctive features of FIA as compared to conventional continuous flow analysis (CFA) and via selected examples demonstrate some of its unique capabilities, while in the following sections emphasis will be placed on the ensuing generations of FIA, detailing their distinct advantages (and limitations) as compared to FIA. In selecting the examples given, attention has been given to show the versatility of FIA and its sequels particularly within the biotechnological field, including process monitoring. What is of importance in the present context is to demonstrate that the FIA approach, besides allowing automation of chemical assays with high sampling frequencies and minute consumptions of sample and reagent solutions, offers potentials to implement novel applications. Or as one of these authors previously wrote in characterising FIA: "the ultimate test for an analytical approach is not that it can do better what can be done by other means, but that it allows us to do something that we cannot do in any other way" (6). And FIA does exactly that. The only limitation is simply our own ingenuity.

\section{X.2 Fundamentals of Flow Injection Analysis}

As mentioned above, FIA is based on injection, or insertion, of a discrete, well-defined volume of sample solution (usually 20-100 $\mu$ l) into a flowing carrier stream. Yet as already verbalized in the very first FIA-publication it relies on two additional cornerstones, namely: (i) reproducible and precise timing of the manipulation that the injected sample zone is subjected to in the system, from the point of injection to the point of detection, that is, the so-called controlled, or rather controllable, dispersion. And (ii) the creation of a concentration gradient of the injected sample, providing a transient, but strictly reproducible readout of the recorded signal. The eventual peak shaped readout, as monitored by a suitable detection device, is therefore always the result of two kinetic processes which occur simultaneously, namely the physical process of zone dispersion and the superimposed chemical processes resulting from reaction between analyte and reagent species. It is the combination of these features that makes it unnecessary to achieve steady-state conditions, as are essential in conventional CFA. Any point on the path toward the steady-state signal is as good a measure as the steady-state itself, provided that this point can be reproduced repeatedly, and this is certainly feasible in FIA with its inherently exact timing. This, in turn, has not only allowed to perform chemical assays much faster, and hence facilitate higher sampling rates, than in conventional procedures, but more importantly it has permitted to implement procedures which are difficult, or, in fact, impossible, to effect by traditional means. 
Being modular in its operational set-up, virtually any unit operation can be incorporated into an FIA system in order to facilitate the optimal manipulations and ultimate detection of the analyte. Thus, the sample might be subjected to appropriate pre-treatments to separate the analyte species from interfering constituents (e.g., by dialysis or extraction), it can be heated/cooled, suitable chemical reagents can be added downstream to facilitate the desired chemical reaction(s) under optimal conditions, and almost any detection device is amenable to be used. In biotechnological applications, sampling is performed by exploiting a sterile barrier for removal of suspended matter, high molecular weight species or cells (7). The immediate consequences of this sample pretreatment is the effective stopping of any further metabolism in the collected sample and the feasibility to inject a preset volume of sample directly into the detection system without no need for further sample clean-up. The sterile barrier is usually composed of a flow-through concentric microdialysis probe operating under convective-controlled transport $(8,9)$. The microdialysis probe can be introduced either directly into the reactor or implemented into an external by-pass loop in order to minimize membrane fouling. When monitoring parameters in fermentation broths, it is however important to reduce both residence time in the loop and the ratio of loop volume to working volume in the bioreactor to prevent any effect on the performance of the microbial culture in terms of substrate availability due to the recirculation process (10). It should be borne in mind that yields of flow-through dialysis are frequently below $15 \%$ wherefore dialysis modules/probes or filter probes have been tailored successfully to bioreactors for in-line dilution of target species $(11,12)$.

Moreover, since only one sample is handled at a time in FI set-ups, the inter-sample washout is efficient and there is no cross sample contamination. In addition, because the wash-to-sample ratio is high, the sample contact time with the detector is short, which is especially advantageous for biosensor applications, as the analytical reaction often reduces the life of the sensor (sensor wearoff) (7).

While much of the attention in using FIA (or just FI, to emphasise that it is a conceptual approach, in addition to a means of performing analysis) initially was set on the feasibility of achieving high sampling rates, as facilitated by exploiting transient rather than conventional steady-state signals, the focus was soon shifted to exploitation of the concentration gradient created, which, as a result of the axial and radial dispersion processes, in reality corresponds to an innumerable number of sequential liquid segments, representing all concentrations from zero to the maximum of the FI peak readout, each of which, as related to a fixed delay time (as measured from the time of injection), potentially can be used for the analytical readout. This, in turn, gave rise to a number of gradient methods (13) as briefly outlined in Table 1, among which especially should be highlighted the stopped-flow method (Fig. 2), which either can be used to gain increased reaction time without dilution (dispersion) of the injected sample, or, when stopping a part of the sample/reagent mixture within the flow-through cell, for sensitivity improvement as well as for measurement of reaction rates. The second approach has proven to be a very powerful tool in many contexts and implemented in the various generations of flow injection (14). Not the least for bioanalytical assays encompassing investigation of cellular activities $(15,16)$ and enzymatic procedures for determination of both substrates and enzymatic activities $(17,18)$, where the latter one traditionally has been very difficult to execute.

Later followed the introduction of methods relying on detection by bio- and chemiluminescence, where alpha and omega is the inherent and accurate timing of the FI-manifold, thus allowing to relate the maximum intensity of the generated transient light emission to the analyte concentration 
(see below). These very sensitive analytical procedures, which prior to the introduction of FI virtually were non-existent, have blossomed to the extent that more than 2000 publications have emerged in the scientific literature over the years, thus accounting for ca. $11.5 \%$ of all the published FI-papers (2). Essentially, these assays are all based on enzymatic conversion procedures, and these types of kinetic modus operandi are, in fact, some of the most frequently encountered ones. In the beginning primarily relying on the use of solubilised enzymes, but later predominantly via immobilised enzymes, taking advantage of the fact that the costly enzymes, even though they are participating in the reactions with the substrate, are not consumed and thus can be reused.

Exploiting the precise and reproducible timing in FI, the formation of intermediate/metastable constituents, which, in contrast to the ultimately generated products, exhibit specifically attractive analytical characteristics, have been utilised to serve for the analytical readout (14), an approach that is totally impossible to make use of in a batch system. Among the many exciting novel techniques are also found the so-called kinetic discriminating schemes, where, even subtle, differences in the reaction rates of occurring chemical reactions judiciously are exploited $(19,20)$ (see section below).

\section{X.2.1. Dispersion and dispersion coefficient}

The dispersion in an FI-system is quantified by the dispersion coefficient $D$, which is defined as the ratio of the concentrations of sample material before $\left(\mathrm{C}^{\circ}\right)$ and after $(\mathrm{C})$ the dispersion has taken place in that element of fluid that yields the analytical readout, that is: $D=\mathrm{C}^{\mathrm{O}} / \mathrm{C}(14)$. The dispersion can be manipulated by the physical dimensions of the FI-manifold used (e.g., length and i.d. of tube, pumping rate and number of merging points), as dictated by the analytical task to be fulfilled. Thus limited dispersion $(D=1-2)$ is used when the injected sample is to be carried to a detector in undiluted form, that is, the FIA system serves as a means of rigorous and precise transport and sample presentation to the detection device (such as an ion-selective electrode or an atomic absorption spectrometer). Medium dispersion $(D=2-10)$ is employed when the analyte must mix and react with the carrier/reagent stream to form a product to be detected, while large dispersion $(D>10)$ is used only when the sample must be diluted to bring it within the dynamic measurement range of the detection device, which is imperative in a vast number of analyzers for determination of target species in cultivation media $(7,11)$. Reduced dispersion $(D<1)$ implies that the concentration of the sample detected is higher than the concentration of the sample injected, that is, on-line preconcentration is effected (e.g., by means of liquid or by solid-phase extraction or by coprecipitation). The latter procedures have especially gained momentum for selective determination of ultra-low levels of metals acting as potential inhibitors of enzyme reactions (see section below on SI-LOV).

\section{X.3.Selected Bioanalytical Applications Exploiting FI}

In the following will be mentioned some bioassays where the conditions of the FI- system are manipulated so that the dispersion is optimal for the given purpose. As a good example of systems exploiting limited to small medium dispersion may serve the use of sensors (ion-selective electrodes or biosensors) (7,21). In potentiometry it is observed that many ion-selective electrodes (ISE) operated in the dynamic mode facilitate fast and reproducible readout. ISEs are, however, generally characterised by fairly long response times to reach steady-state conditions, and therefore it can be difficult to ascertain exactly when to make the readout by manual operation. In FI this decision is left entirely to the system, because the sample reaches the detector after a time governed exclusively by the manifold used. Besides, the well-known fact that many ISEs are more or less prone to 
interference from other ions can in many cases be eliminated, or considerably reduced, when making the measurement under FI-conditions. Thus, by taking advantage of the short residence time and exposure time of the sample in the FI-system, it is often possible, via kinetic discrimination between the ion under investigation and the interfering species (which frequently exhibit longer response times), to improve the selectivity and hence the detection limit of the sensor.

The same concept of manipulating the sample exposure time can be extended to more complex sensors such as enzyme sensors, in which a membrane containing one or more immobilized enzymes is placed in front of the active surface of a transducing element. The analyte is transported by diffusion into the membrane and here degraded enzymatically, forming a product which can then be sensed by the transducer. Flow-injection biosensors for bioreactor monitoring usually combine oxidase or dehydrogenase-linked enzymic reactions with amperometric detection of molecular oxygen depleted or hydrogen peroxide generated (22-24). A common configuration for single parameter measurement involves a sandwich-type membrane configuration with the enzyme embedded in the intermediate layer in order to minimize enzyme leaching and microbial attack while preventing reducing or oxidizing interfering species from reaching the electrode surface (21). Sequential or simultaneous multiparametric detection can be accomplished by the use of either various enzymic sensors in a parallel or series configuration (23) or integrated electrode arrays (2527), respectively.

A condition for obtaining a linear relationship between the concentration of analyte and analytical signal is, however, that pseudo-first-order reaction conditions are fulfilled, that is, the concentration of converted analyte reaching the detector surface must be much smaller than the Michaelis-Menten constant. Since this constant for most enzyme systems is of the order of $1 \mathrm{mmol} / \mathrm{L}$, and many sample matrices (e.g., substrates for culture broths) contain much higher analyte concentrations, the use of enzyme sensors in static (batch) systems often calls for complicated use of additional membrane layers aimed at restricting diffusion of analyte to the underlying enzyme layer, which in turn implies slow response, or, in case of electrochemical detectors, calls for chemically modified electrodes where the electron transfer is governed by appropriate mediators.

However, when operated in FI, the degree of conversion can be simply adjusted by the time the analyte is exposed to the enzyme layer, and therefore the amount of converted analyte can be regulated directly by adjusting the flow rate of the FI-system (28). Thus in an FI-system, used for the determinations of glucose by means of an amperometric sensor incorporating glucose oxidase, it was shown (Fig. 3), that by increasing the flow rate from 0.5 to $1.0 \mathrm{~mL} / \mathrm{min}$ the linear measuring range could readily be expanded from 20 to $40 \mathrm{mmol} / \mathrm{L}$ glucose (28). Of course there is a price to be paid for this convenience, and as seen on Fig. 2 it is that the sensitivity is slightly decreased. This approach has found much use in ensuing years. Thus, for instance Tsukatini and Matsumoto (29) have used it for the fluorometric determination of pyruvate, and in turn assay of acetate, citrate and L-lactate.

Additionally, the exposure time can be exploited for kinetic discrimination, taking advantage of differences in diffusion rates of analyte and interfering species within the membrane layer of the electrode. This was very elegantly demonstrated in the above-mentioned system (28), where total spatial resolution of the signals due to glucose and paracetamol could be achieved, even when paracetamol was added at excessive levels. Besides, attention should be drawn to the fact that the operation of a (bio)sensor in the FI mode ensures a constant monitoring of the sensor itself, that is, 
while the recorded signal is a measure of the concentration measured, the baseline readout indicates directly the stability of the sensor.

In this context it should be mentioned that considering the diversity of the chemical and physical events that can be involved in the function of a biosensor, in addition to satisfying individually dictated reaction parameters, it is not surprising that operational compromises frequently have to be made for practical synchronization of all the processes required (30). Thus, the optimal $\mathrm{pH}$ used for the enzymatic degradation process might not (as is often the case) be identical to the preferential $\mathrm{pH}$ value for detection of the product generated. For example if a gas sensor covered with a membrane of glutaminase is employed for determination of L-glutamine, the measurement of the ammonia evolved will require a $\mathrm{pH}$ value 2-3 units higher that that of the enzymic reaction. Furthermore, and in order to implement functions such as periodic calibration, conditioning and possible regeneration of the biosensor, and, very importantly, to yield the freedom to select the optimum detection means, it is advantageous to use these devices in the FI-mode (31). Besides, utilization of biosensors in FImanifolds allows the sample to be modified/manipulated as required for execution of various unit operations such as separation, automatic dilution, or (bio)chemical derivatization prior to the final detection step. In fact, the ideal solution is to use an FI-system where the enzymatic degradation of the sample and the detection step are separated and can be individually optimised, that is, the entire system flow system is be considered as a biosensor/biosensing device (32). For the very same reasons, the emphasis on the development of biosensors has in recent years shifted from fabricating devices which can be used as probe sensors, similarly to the approach of ISEs in batch assays, to development of flow-through sensor systems.

When applied in the FI-mode the use of immobilized enzymes offers not only the selectivity, economy and stability gained by immobilization, but also ensures that strict repetition, and hence a fixed degree of turnover from cycle to cycle, is maintained. Two types of reactors have been incorporated and evaluated in flow set-ups, namely, packed-bed reactors with the enzyme immobilised on controlled-pore glass (33-35), and wall-coated open tubular reactor with the enzyme attached to the inner surface of nylon tubing or silica-fused capillaries (36-38). The former one features larger surface area and therefore larger enzyme load per unit volume, yet progressively tighter packing of the reactor might lead to increased backpressure with the consequent deterioration of the analytical performance of the analyzer. Thus, whenever several enzymic reactions are involved, co-immobilization strategies are preferred over coupling of various reactors in series. Several examples are found in literature referring to biotechnological applications, mostly comprising the oxidase/peroxidase $(35,39)$ or dehydrogenase/aminotransferase $(34,40)$ pairs. Both optical and electrochemical detectors can be used to monitor the reaction(s). Thus, for dehydrogenases, involving $\mathrm{NAD}^{+} / \mathrm{NADH}$, spectrophotometry $(34,40)$ or fluorometry $(29)$ is directly applicable, while for oxidases, which give rise to the generation of hydrogen peroxide, amperometric measurements or spectrophotometric detection of a chromogenic redox reagent can also be employed $(35,39)$.

In open reactors, the surface area per unit volume is orders of magnitude lower than that packed reactors and thus the enzyme load is much lower. Longer reactors are needed for attaining similar sensitivity, yet compromise should be taken to prevent undue sample/reaction product dispersion. The most relevant asset is the negligible flow impedance increase even after long operational protocols (41). Therefore, this alternative has found applications for monitoring high concentrations of dissolved substrate components, but also for products of bacteria or yeast cultivations when coupled to highly sensitive detection systems such as those involving luminol-based 
chemiluminescence reactions $(35,36)$. Analyte detection via chemiluminescence is particularly fascinating and attractive, not merely because of the potentially high sensitivity achieved, but the wide dynamic range of luminescent procedures and fairly simple instrumentation needed. Furthermore, luminescence has an added advantage over most optical procedures: as light is produced and measured only when sample is present, there is generally no problem with blanking. However, the radiation in luminescence reactions is most often emitted as a flash which rapidly decreases, and for this reason the conventional approach of quantification has been to integrate the intensity over a fixed period of time and relate this to the amount of analyte. It is obvious, however, that if the measurement of the intensity of light $\mathrm{dE} / \mathrm{dt}$ can be made under precisely defined and reproducibly maintained conditions so that all samples are treated, physically and chemically, in exactly the same manner (i.e., the measurements can be taken repetitively at identical delay times $t_{i}$, Fig. 4), it is possible directly to relate any $\mathrm{dE} / \mathrm{dt}$-value (and preferably the one corresponding to the maximum emission, $\Delta \mathrm{t}$, Fig 4 ) to the analyte concentration. This is feasible by means of FI, and therefore the combination of luminescence and FI has, in fact, revolutionised the application of bioand chemiluminescence as analytical chemical detection procedures (42).

Numerous applications of enzyme assays in FI have been reported, advantage being taken of the fact that these components constitute the selective link in the analytical chain which therefore becomes selective overall (43). Some recent reviews contain extensive up-to-date of FI-enzymic assays and FI-biosensing $(7,21)$. Seen in this context, it is apparent that FI not only constitutes a complimentary facility to (bio)sensors, but in many cases offers itself as an attractive alternative.

\section{X.4 The Role of FI for Process Analysis/Monitoring}

In emphasising the many analytical chemical possibilities that FI offers, it is of interest to end this section by drawing attention to an application of this concept that at an early stage promised to become very important, that is, its use for monitoring purposes notably in areas such as process control/development and optimisations. Traditionally, most industrial processes have been surveyed off-line in the laboratory after withdrawal of separate samples. However, for an efficient process monitoring and control, the time delay, the limited reliability, and the man power needed for analysis of a large number of samples are crucial parameters. Already in 1982, the first paper on utilisation of FI for process control appeared (44), and in their FI-monograph Ruzicka and Hansen (14) predicted that FI would turn out to play a major role in this area, because it potentially offered a number of advantages, the most significant ones being: (a) Because every FI readout inherently consists of a peak that goes from the baseline, through a maximum, and back to the baseline again, one can not only monitor the analyte species via the reaction taking place in the manifold (i.e., via the peak maximum), but one can at the same time control the performance of the analytical system itself (i.e., by the baseline); (b) FI allows occasional recalibrations or updates/checks of the calibration curve at will, that is, standards can be injected at any time desired, which is a necessity particularly if very complex samples are at hand; (c) FI is very economical in sample consumption which not the least is important when used in pilot plant scale experiments - even if the procedure applied calls for the use of a reversed FIA assay (rFIA, i.e., where the reagent is injected into the sample); and (d) FI permits appropriate pretreatment of the sample prior to analyte detection, that is, subjecting the sample to dialysis, filtration, extraction or other separation procedures, thereby eliminating potentially interfering species.

The ideal solution for process monitoring would be, of course, to implement an in situ totally selective (in fact, "specific") detection device (sensor). As this is virtually impossible (a pH 
electrode and a thermometer possibly constituting the only exceptions coming close to be meet this criteria), and considering the remarks stated above, near real-time monitoring must necessarily be made in an ex-situ set-up (7). Facilitating this has in the literature been called by several names, such as "on-line" or "in-line" (which in this context obviously are wrong). Since a sample must be in some manner withdrawn from the system (e.g., using microdialysis probes) and then analysed, the proper tag would be either "off-line" or "at-line" detection. When using FI as the analysis system, the latter term is preferential, because it implies that the determination is made at the site and in as close as possible to real-time.

In 2001 and 2003 Workman et al. $(45,46)$ presented comprehensive compilations of FI-literature for process control applications. Although some additional papers have appeared in the literature since then (e.g., (35), it is evident that FI has not played the role expected in this field. Seen in retrospect the reason for this is simply that the commercial (and homemade) FI apparatus available often was designed for the laboratory environment, where continuous supervision of its function was a norm, and therefore was not sufficiently reliable for application in industrial settings (47). In fact, it took two decades and the development of sequential injection analysis to resurrect the idea in earnest, that is, by replacing the peristaltic pumps with a single syringe pump, the injection valve with a multiposition valve, continuous flow with reagent saving programmable flow, and human supervision with computer control, that is, the advent sequential injection analysis (SIA or SI) (4). Autonomous SI systems are now deployed in industry as well as in remote locations to provide 24/7 (twenty four hours/seven days a week) monitoring of variety of analytes ranging from spectrophotometric determinations of dyes to fluorescence/enzymatic assays of bacteria coli (48).

\section{X.5 Fundamentals of Sequential Injection Analysis}

While most FI-procedures employ continuous, uni-directional pumping of carrier and reagent streams irrespective of whether a sample is injected or not, which from the point of view of reagent consumption is a drawback, sequential injection analysis (SIA or just SI) is based on using programmable, bi-directional discontinuous flow as precisely coordinated and controlled by a computer $(3,4))$. A sketch of a typical SI-manifold is reproduced in Fig. 1(b).

The core of the system is a multi-position selection valve (here shown as a 6-port valve), furnished with a central rotary communication channel (CC) that can be made to address each of the peripheral ports (1-6), and a central communication line (CL) which, via a holding coil (HC), is connected to a syringe pump operating as the liquid driver. By directing the central communication channel to the individual ports, well-defined and precisely metered sample and reagent zones (typically 5-25 $\mu \mathrm{l}$ ) are initially time-based aspirated sequentially into the holding coil where they are stacked one after the other. Afterwards, the selection valve is switched to the outlet port (here position 5), and the segments are propelled forward towards the detector, undergoing on their way dispersion and thereby partial mixing with each other, and hence promoting chemical reaction, the result of which is monitored by the detector. Notable advantages of SI as compared to FI are in particular that it allows the exact metering of even smaller volumetric volumes (of the order of a few microlitres), which fostered the use of liquid enzymes $(49,50)$ and costly cofactors as demanded in NAD-linked enzymic assays (40). Further, thanks to the use of a syringe pump, SI is much better suited for stopped-flow procedures where a very precisely selected delay time is necessary, and that it readily and reproducibly permits flow reversals, which, in fact, in addition as a mere means of transport, also might be used to promote mixing of sample and reagent(s) and facilitate controlled sample dilution within the HC. 
Besides, it is extremely economical as to consumption of sample and reagents, and hence in waste generation, which nowadays is an important parameter since it is becoming increasingly expensive to dispose of chemical wastes. And since all manipulations are computer controlled, it is easy and simple to reprogram the system from one application to another one, providing great versatility for monitoring multiple variables in fermentation broths $(12,37)$ since all operating protocols such as sample injection, mixing, and separation are controlled precisely by the software without need for physical reconfiguration of the system. However, it is generally difficult to accommodate (stack) more than two reagents along with the sample, although additional reagents might be added further downstream, i.e., by making an FI/SI-hybrid. And due to the use of a syringe pump, SI has a somewhat limited operating capacity, although this in practice rarely is a constricting factor.

Allowing the communication to various peripheral ports at will, SI has proven itself especially useful for monitoring of fermentation processes as facilitated by automated recalibration of the system, injection of quality control standards, performing of standard addition methods, injection of samples from different sampling sites with variable time basis and real-time calculation of actual concentrations of substrates and products as well $(27,51)$. Besides, it has found notable use in pharmaceutical industries, allowing not only for analysis of drug formulations, but particularly facilitating monitoring of drug-dissolution profiles, in-vitro drug-release testing and functional assays for screening of potential drugs (52-54).

\section{X.6 Microfluidic Devices: Lab-on-Valve}

In the Lab-on-Valve (LOV) concept (Fig. 1(c)) advantage is taken of using an integrated micromachined structure (5). The microconduit monolith (which has a diameter of ca. $5 \mathrm{~cm}$, a thickness of ca. $10 \mathrm{~mm}$; a photo of it is shown in Fig. 5(a)), made initially of Perspex, but more recently of hard polyvinylchloride, polyetheretherketone (PEEK) or polyetherimide (ULTEM) for improved chemical resistance to a wide range of organic solvents, is mounted atop of a six- or tenport selection valve. Allowing further downscaling of conventional SI systems, and designed to incorporate all necessary laboratory facilities for a variety of analytical chemical assays, hence the name lab-on-a-valve, it is made to contain mixing points for sample and reagents; working channels for sample dilution, overlapping of zones, sample and reagent(s) incubation and sample purification; and, to the extent possible, a multipurpose flow-through cell for real-time monitoring of the development of the chemical reactions (55). Thus, the LOV unit can readily be devised to incorporate optical detection facilities, that is, devices (namely, diode-array spectrophotometers, USB charged-coupled devices (CCDs), laser-induced spectrofluorimeters or luminometers) where the communications to the detector and/or the light source are made via optical fibres (Fig. 5(b)), and where the position of the fibres can be used to adjust the optical light path of the cell (5). Electrochemical detection has been recently proven feasible by use of the flow-through cell for housing a three-electrode voltammetric unit (16). The microfabricated channel system (typically 1.6 $\mathrm{mm}$ i.d.) is also amenable to admit conventional sized peripheral devices, thus facilitating the hyphenation with a plethora of optical detection techniques and modern analytical instruments (Fig. 5(a)), such as electrothermal atomic absorption spectrometry (56), inductively coupled plasmaatomic emission spectroscopy or mass spectrometry (57), cold-vapor atomic absorption spectrometry (58), electrospray ionization mass spectrometry $(59,60)$, atomic fluorescence spectrometry (61), and, what is especially important for bioseparations and cell technology, to chromatographic/electrophoretic column separation systems coupled to UV-Vis or mass spectrometric detection for multiparametric assays (62-64). Thus the role of the LOV is here to 
serve as a "front end" to execute appropriate sample pretreatments aimed at introducing the analyte optimally into the detection instrument.

A valuable asset of the microflow structure is the microfluidic handling of not only metered volumes of solutions but solid suspensions as well for exploitation of heterogeneous chemical reactions (Fig. 5(b)). The LOV approach fosters the in-valve manipulation of sorbent materials carrying suitable surface moieties in order to generate packed column reactors for micro-scale solidphase extraction $(65,66)$, or microaffinity chromatography $(67)$, in a permanent or a renewable flow fashion, that is, the so-called bead-injection (BI) scheme $(68,69)$, depending on the particular chemical assay. In short, microcolumns are in-situ generated by aspirating beads with particular surface characteristics and particle sizes, advantage being taken of the fact that the sorbent can be manipulated exactly as when handling liquids. The solid entities can even be automatically transported between different column positions within the LOV, their retention within the columns, as reported elsewhere (65), being facilitated by fitting the column positions with appropriate stoppers (Fig. 5(a)), which will keep hold of the beads, yet allow solutions to flow freely. Following sample loading and clean-up protocols, appropriate eluents can be aspirated, and the eluate propelled to either the flow-through cell or an external detection device, as sandwiched by air or immiscible liquid segments in order to preserve its integrity $(70,71)$.

In order be operated in the BI-LOV fashion, there are some requirements to the bead materials, that is, they should be perfectly spherical (i.e., in the form of globe-shaped particles; they should be uniform in size distribution (falling within a range of 40-150 $\mu \mathrm{m}$ ); and they should possess a density close to that of water. Nowadays, a wide array of bead particles (predominantly with a core of Sephadex type copolymers) with various surface characteristics are commercially available, and in the following section will be described procedures for real-time monitoring of cellular activities via immobilized live cells $(15,72)$, isolation and on-column fluorimetric detection of DNA $(15)$, optimization of immobilization protocols for proteins (74), as well as investigation of biomolecular association and dissociation processes as exploited in enzyme-linked immunosorbent assays (75) and affinity chromatographic methods $(59,60,76)$. Yet before that, it might be of interest to compare the LOV with the socalled micro-total analysis systems ( $\mu$ TAS) (77), or as they lately have been termed Lab-on-a-Chips (LOC), which are exploited for bionanotechnological applications $(78,79)$.

The interest for $\mu \mathrm{TAS} / \mathrm{LOC}$ microstructures was actually stimulated in the early 90 's by electrical and mechanical engineers, who parallelly and intensively focused on miniaturisation of flow devices (77). The channel network, which is made by various sophisticated procedures, such as micro-drilling, etching, photolithography, or laser erasing, is impressively exact and reproducible, allowing different channels profiles to be obtained. In many instances it can be made in inexpensive materials, namely silicon, glass, polymethyl methacrylate and polydimethylsiloxane, and massproduced at low cost, in fact, at much lower expenditures than the LOV. However, the microfluidic devices are usually dedicated, that is, they have fixed architecture for predetermined chemistries. However, as opposed to what applies for LOC systems, LOV practitioners are not being dictated by a fixed architecture of their microfluidic devices in order to implement chemical assays, but are able to control the parameters at will in order to adapt the physical movements of the liquids to the chemistries to be implemented. This, very importantly, implies that they can intelligently exploit the interplay between thermodynamics and kinetics, which is of utmost relevance when dealing with chemistries that are not fast or instantaneous, or even require stepwise reaction sequences. In this context it is interesting to note that the authors of microfluidic devices are customarily demonstrating the capacity of their LOCs for fast, single step bioassays $(80,81)$, which leaves a 
multitude of very interesting and intriguing chemistries unexplored. Further, the small dimensions of the microchip channels pose a severe problem for sensitive and reliable absorbance measurements (82).

Further, LOV practitioners possess the ability to manipulate the conditions in such a manner that the axial dispersion is minimized at the expense of the radial dispersion, thereby ensuring good mixing of sample and reagent within the individual microfluidic segments. This can readily be accomplished by destabilising the laminar flow pattern via the geometry of the flow conduit, e.g., the sample/reagent path is made to be nonlinear and/or non-uniform in diameter $(5,83)$, and, as opposed to LOCs, by designing appropriate flow programming protocols which might comprise flow reversals, flow acceleration, stopped flow and bursts of high flow velocity. These tools promote fast radial mixing, while axial mixing is controlled by choice of the injected volumes, and by the length travelled by the plug in forward and reversed direction. Since incubation times are promoted by stopping the flow (either in the holding coil or better yet in the LOV flow-through cell), the length of the conduit through which the sample will travel can be minimized. At the same time, by increasing the conventional narrow flow channels in LOCs from 10-100 $\mu \mathrm{m}$ up to $1.6 \mathrm{~mm}$ in LOV, the surface to volume ratio in LOV is reduced, thus minimizing adsorption of macromolecules on the walls of the microbore conduit. In addition, the low flow resistance of short and wide flow conduits allows precise flow manipulation, and the use of ultra fast bursts of flow that can wash out the channels rapidly and easily remove stray air bubbles or clogging particles. Readers are referred to a recently published comprehensive review article for a detailed and critical comparison of LOV and LOC micromachined units (84).

In the following are detailed a few practical examples of using the SI-LOV approach for biochemical assays and bioseparations.

\section{X.7 Selected Bioanalytical Applications Exploiting SI-LOV}

\section{X.7.1 Exploiting the Stopped-Flow Approach}

As mentioned earlier, the stopped-flow technique (Fig. 2) is a very powerful tool for determining analyte species participating in enzymatic or cellular assays (14). Relying on manipulating the concentrations of the constituents participating in the chemical reaction so that these can be considered constant during the measurement (for instance by recording absorbance as depicted in Fig. 2), that is, pseudo-zero reaction conditions are met $\left(\mathrm{dC} / \mathrm{dt}=\mathrm{k}^{\prime} \mathrm{C}\right.$, where $\mathrm{C}$ is the concentration of analyte), the slope of a plot of the analytical signal (in casu Absorbance) against the time will be directly proportional to the concentration of analyte. At least within a certain time frame, which is also why the procedure is termed measurement of initial reaction rates. In practice, the progression in the recorded detector signal ( $\Delta$ signal) over a fixed period of time $(\Delta t)$ is used. Furthermore, the plot will directly reveal within which range the reaction conditions are fulfilled (i.e., slope is constant), and which time interval thus is applicable for measurement. An added and unique advantage of this approach is that automatic blanking is obtained, because only the generated signal ( $\Delta$ signal) within in the time interval is utilised for quantification. When incorporated within the LOV format, where very minute consumptions of sample and reagents are required, and where one can take advantage of the extremely accurate operation of the incorporated syringe pump for aspiration and propelling of solutions, the approach presents itself as an ideal solution for process monitoring of both large and small scale bioreactors $(5,85)$. 
Several LOV-applications of the stopped-flow approach have appeared in the literature. Thus, with an LOV system as that depicted in Fig. 5(b) and using detection by spectrophotometry, Wu et al. (60) employed it for monitoring ammonia, glycerol, glucose and free iron in a fermentor, while Chen and Ruzicka (18) used it for determination of glucose and ethanol. While the glucose assay was based on catalytic degradation of glucose oxidase leading to the generation of hydrogen peroxide, which was subsequently reacted with 4-aminoantipyrine to form a quinoneimine dye (18), ammonia was assayed via the Berthelot indophenol blue method with salicylate and hypochlorite as reagents. In Fig. 6 is shown the sequence of the aspirated sample and reagents, where $\mathrm{NH}_{3}$ represents the sample, the reagent is salicylate, while the spacer is a plug of carrier solution (diluted aqueous solution of detergent) inserted for promoting sufficiently partial mixing of sample and reagents and allowing a suitable delay time before the stopped-flow measurements. As shown in the lower part of the Fig. 6, the stopped-flow readouts are very reproducible.

\section{X.7.2 Bioseparations and Cellular Assays}

Combining LOV and bead injection (BI), Ruzicka and coworkers have in particular focused on cellular analyses and immunoassays $(15,67,74-76)$. The former are being used for screening of potential drugs by in-vitro evaluation of biological responses. Cells are cultivated onto polysaccharide microbeads and thus a representative number of cells within the LOV is ensured using a minute volume of bead suspension. Cellular responses are evaluated by determination of different parameters, such as release of cytosolic calcium, intracellular or extracellular $\mathrm{pH}(15)$ metabolic oxygen consumption (16), lactate extrusion (72) or glucose consumption (86).

Immunoassays have been miniaturised within microfluidic devices for quantification of biomolecules by either monitoring them as they are captured on microbeads bearing antigen species as entrapped within the LOV flow cell via UV/VIS spectrophotometry or fluorometry (see Fig. 7A) or by detecting them as they are eluted from the beads (Fig. 7B). While the first approach can be viewed as "on-column spectroscopy" $(15,74,75)$, the latter one can be considered as miniaturized bioaffinity chromatography $(59,60,67)$. Both methods employ in-valve bead injection analysis with renewable microcolumns and identical analytical instrumentation, whereby they can be exploited in a complementary fashion to get further knowledge on biomolecular association and dissociation reactions $(76,88)$. The microaffinity chromatography in the LOV format has been demonstrated for separation of immunoglobulins or nucleic acids, as based on molecular recognition between a site fixed on the stationary phase and the target species that is being captured, while unwanted matrix components, such as salts and proteins, are washed out by the mobile phase. In contrast to conventional immunoaffinity chromatography it is readily feasible to control the operational $\mathrm{pH}$, which is a very critical parameter, and compared to on-column spectroscopy, LOV-chromatography on a renewable bead column is more robust, since the volume of the beads captured within the microcolumn is far less critical, and also because the target analyte is eluted and monitored in solution and not on bead surfaces, thus precluding light scattering effects $(67,76)$. Furthermore, by using a short pulse of eluant, the front elution contains almost all target molecules, yielding excellent limits of detection. Yet, the most severe limitation of microaffinity chromatography is that it cannot monitor antibodies when remaining immobilized irreversibly on the bioligand bearing beads. On the contrary, bead injection spectroscopy monitors the sorption process, whereby the elution of target species is not a must since beads can be automatically withdrawn following recording of the spectroscopic readout $(74,76)$.

In this context it should also be mentioned that the SI-LOV system has been interfaced to capillary electrophoresis (CE) with UV detection for inorganic anion and protein separation $(62,63)$. In this 
case, the multi-purpose flow cell was reconfigured to act as a front end between the microfluidic device and the CE separation module. The microfluidic property of LOV did not merely provide an efficient sample delivery conduit for the CE system with various sample injection modes, including electrokinetic, hydrodynamic and head column field amplification sample stacking (98), but at the same time served as a versatile means of sample pretreatment and chemical derivatization (e.g., protein labelling) (63) to facilitate the ensuing CE separation.

A detailed compilation of the work by Ruzicka and his coworkers can be found on the CD-ROM published by Ruzicka (89).

\section{X.7.3 DNA Assays}

A very active research group at Northwestern University in Shenyang, China, headed by Professor Jianhua Wang, have over the past few years published a series of papers focused on determination and/or purification of DNA exploiting the inherent features of LOV. In the first communication (90), and using a LOV similar to the one shown in Fig. 8, they described a spectrophotometric procedure for DNA assay, where a small amount of crystal violet solution $(10 \mu \mathrm{l})$ was de-coloured inside the flow cell of the LOV in the presence of $5 \mu 1 \lambda$-DNA/HindIII within a certain $\mathrm{pH}$ range, the decrease in absorbance of the crystal violet solution being measured at $591 \mathrm{~nm}$ via optical fibers and employed as the basis of quantification. Obtaining a detection limit of $0.07 \mu \mathrm{g} \mathrm{ml}^{-1}$, this work was supplemented by a procedure based on fluorescence measurement (91), where sub-nanoliter to a few micro-liters of DNA sample and ethidium bromide (EB) solutions were introduced into the LOV, resulting in the formation of a DNA-EB adduct, which afterwards was excited in the versatile flow cell of the LOV by a $473 \mathrm{~nm}$ laser beam, the emitted fluorescence being monitored in-situ via optical fibers. By using this approach the detection limit was further decreased, that is, to $0.006 \mu \mathrm{g}$ $\mathrm{ml}^{-1}$ by affixing the aspirated sample volume to $2.0 \mu \mathrm{l}$.

In a very recent publication (92), this research group has exploited the LOV for DNA separation/purification via solid-phase extraction with a silica microcolumn packed within an LOV microchannel. By proper selection of the sample loading and the elution media, the complex matrix components in human whole blood, including proteins, could be completely eliminated. The DNA purification process was monitored on-line by using laser-induced fluorescence at $610 \mathrm{~nm}$ in a demountable side part of the LOV unit incorporating optical fibers (Fig. 8). The practical applicability of the entire system was demonstrated by separation/purification of $\lambda$-DNA in a simulated matrix and human blood genetic DNA by performing in-valve SPE, in situ monitoring of the purified products via in-situ fluorometric detection of DNA-EB, and postcolumn PCR amplification. It was demonstrated to offer significant advantages over chip-based separation/purification systems based on the same principle in terms of precision, sampling frequency as well as robustness. The employment of the bead injection technique facilitated automatic injection and withdrawal of the solid phase material in the LOV-based purification system, as opposed to lab-on-a-chip microdevices where renewal of solid substrates is not feasible and thus the entire microchip should be discarded and replaced by a new one after short term operation.

The Chinese group (93) and the one headed by Professor Luque de Castro (94) in Spain have most recently compiled comprehensive reviews on bioanalytical applications of LOV, including cellular analysis, immunoassays, affinity chromatography, DNA separation/purification, and enzymatic assays. Readers are encouraged to consult these articles for further details. 


\section{X.8 Conclusion and Perspectives}

Being based on transient measurements and exact and reproducible timing, FIA and its sequels SIA and LOV have turned out to open an array of novel possibilities within bioanalytical sciences. A compilation of recently published automatic procedures for monitoring of fermentation broths are presented in Table 2. Although not exhaustive, it gives a rather good impression of the variability of the species determined and the techniques applied. In general it should be stressed that not only do the procedures consume very small amounts of sample and reagent solutions, and thus lead to generation of minute volumes of waste, but, more importantly, they allow entirely new and unique approaches to be implemented, which are not possible with conventional batch or continuous flow procedures.

The ultimate goal in modern (bio)chemical analysis is to identify individual analyte species in a given complex sample with sufficient selectivity and sensitivity which, in turn, often calls for appropriate sample pretreatments or hyphenation of various selective detectors. Such schemes might entail physical/temporal separation of individual compounds via chromatographic or electrophoretic techniques for speciation purposes or coupling of enzyme-based sensors in series, but might also involve the separation of the analytes from potentially interfering matrix constituents, or the execution of sample preconcentration protocols. Or, in fact, as most often encountered in practice, a combination of all strategies. Here the SI-LOV approach presents itself as an ideal vehicle to act as the 'heart' of the system, because it is totally automated, miniaturised and fully computer-controlled. In SI-LOV, one has the advantage of being able to attach external units to facilitate individual operations, such as chromatographic columns for spatial separation of individual (bio)components, or for applying external energy sources such as UV light, or ultrasound or microwave radiation in order to effect desired reactions. But most importantly, a proper hyphenation will allow the implementation of intelligent chemistries, where advantage can be taken by the fact that the on-line systems operate under dynamic conditions so that one can exploit the interplay between thermodynamics and kinetics. Thus, what is needed in future applications is a realisation of what this interplay implies, particularly in terms of facilitating determination of (bio)chemical species in culture media or live cells, because this is exactly what differentiates the on-line LOV microanalysers from their batchwise counterparts - and, in fact, the LOCs. 


\section{List of Cited Publications}

1. J. Ruzicka and E.H. Hansen, Anal. Chim. Acta 78, 145-157 (1975).

2. E.H. Hansen, Flow Injection Bibliography, http://www.fialab.com/; (2008).

3. J. Ruzicka and G.D. Marshall, Anal. Chim. Acta 237, 329-343 (1990).

4. C.E. Lenehan, N.W. Barnett, and S.W. Simon, Analyst 127, 997-1020 (2002).

5. J. Ruzicka, Analyst 125, 1053-1060 (2000).

6. E.H. Hansen, Quim. Anal. 8, 139-150 (1989).

7. V. Vojinovic, J.M.S. Cabral, and L.P. Fonseca, Chem. Ind. \& Chem. Eng. Q. 13, 103-116 (2007).

8. N. Torto, L. Gorton, T. Laurell, and G. Marko-Varga, Trends Anal. Chem. 18, 252-260 (1999).

9. N. Torto, T. Laurell, L. Gorton, and G. Marko-Varga, Anal. Chim. Acta 379, 281-305 (1999).

10. L.H. Christensen, J. Nielsen, and J. Villadsen, Anal. Chim. Acta 249, 123-136 (1991).

11. I. Ogbomo, R. Kittsteiner-Eberle, U. Englbrecht, U. Prinzing, J. Danzer, and H.L. Schmidt, Anal. Chim. Acta 249, 137-143 (1991).

12. R.A.S. Lapa, J.L.F.C. Lima, and I.V.O.S. Pinto, Food Chem. 81, 141-146 (2003).

13. E.H. Hansen, Fresenius' Z. Anal. Chem. 329, 656-659 (1988).

14. J. Ruzicka and E.H. Hansen, Flow Injection Analysis, $2^{\text {nd }}$ Edn.; Wiley-Interscience, New York, 1988

15. H.A. Erxleben, M.K. Manion, D.M. Hockenbery, L. Scampavia, and J. Ruzicka, Analyst 129, 205-212 (2004).

16. I. Lähdesmäki, Y.K. Park, A.D. Carroll, M. Decuir, and J. Ruzicka, Analyst 132, 811-817 (2007).

17. O. Cos, J.L. Montesinos, J. Lafuente, C. Sola, and F. Valero, Biotechnol. Lett. 22, 1783-1788 (2000).

18. Y. Chen and J. Ruzicka, Analyst 129, 597-601 (2004).

19. Z.-L. Fang, Gas-Liquid Separation. In Flow-Injection Separation and Preconcentration; VCH Verlagsgesellschaft mbh: Weinheim, 1993; Ch. 5, 129-157.

20. E.H. Hansen and M. Miró, Trends Anal. Chem. 26, 18-26 (2007).

21. M.I Prodromidis and M.I Karayannis, J. Flow Inject. Anal. 21, 5-10 (2004).

22. M. Niculescu, T. Erichsen, V. Sukharev, Z. Kerenyi, E. Csoregi, and W. Schuhmann, Anal. Chim. Acta 463, 39-51 (2002).

23. M.A. Kumar, M.S. Thakur, A. Senthuran, V. Senthuran, N.G. Karanth, R. Hatti-Kaul, and B. Mattiasson, World J. Microbiol. Biotechnol. 17, 23-29 (2001).

24. K.B. Male, P.O. Gartu, A.A. Kamen, and J.H.T. Luong, Anal. Chim. Acta 351, 159-167 (1997).

25. R.W. Min, V. Rajendran, N. Larson, L. Gorton, J. Planas, and B. Hahn-Hägerdal, Anal. Chim. Acta 366, 127-135 (1998).

26. M. Held, W. Schuhmann, K. Jahreis, and H.L. Schmidt, Biosens. Bioelectron. 17, 1089-1094 (2002).

27. W. Schuhmann, H. Wohlschlaeger, J. Huber, H.L. Schmidt, and H. Stadler, Anal. Chim. Acta 315, 113-122 (1995).

28. B.A. Petersson, H.H. Andersen, and E.H. Hansen, Anal. Lett. 20, 1977-1994 (1987).

29. T. Tsukatani and K. Matsumoto, Talanta 69, 637-642 (2006).

30. E.H. Hansen, Talanta 41, 939-948 (1994).

31. K. Lau, Encyclop. Anal. Science, $2^{\text {nd }}$ Ed.; Elsevier, Netherlands, 2005; 224-231.

32. E.H.Hansen, J. Mol. Recogn. 9, 316-325 (1996). 
33. R.L.C. Chen and K. Matsumoto, Anal. Chim. Acta 308, 145-51 (1995).

34. C. Mayer, A. Frauer, T. Schalkhammer, and F. Pittner, Anal. Biochem. 268, 110-116 (1999).

35. V. Vojinovic, C.R. Calado, A.I. Silva, M. Mateus, J.M.S. Cabral, and L.P. Fonseca, Biosens. Bioelectron. 20, 1955-1961 (2005).

36. S. Benthin, J. Nielsen, and J. Villadsen, Anal. Chim. Acta 261, 145-153 (1992).

37. R.W. Min, J. Nielsen, and J. Villadsen, Anal. Chim. Acta 312, 149-56 (1995).

38. L.-C. Wu and C.-M. Cheng, Anal. Biochem. 346, 234-240 (2005).

39. V. Vojinovic, F.M.F. Esteves, J.M.S. Cabral, and L.P. Fonseca, Anal. Chim. Acta 565, $240-$ 249 (2006).

40. H.-C. Shu, H. Hakanson, and B. Mattiasson, Anal. Chim. Acta 300, 277-85 (1995).

41. J. Nielsen, K. Nikolajsen, S. Benthin, and J. Villadsen, Anal. Chim. Acta 237, 165-175 (1990).

42. A.C. Calokerinos and L.P. Palilis, Chemiluminescence in Flow Injection Analysis. In A.M. García-Campaña and W.R.G. Baeyens (Eds) Chemiluminescence in Analytical Chemistry, Marcel Dekker, NY, 2001; Ch.12, 321-348.

43. E.H. Hansen, Anal. Chim. Acta 216, 257-273 (1989).

44. T. Korenaga and H. Ikatsu, Bunseki Kagaku 31, 135-140 (1982).

45. J. Workman, K.E. Creasy, S. Doherty, L. Bond, M. Koch, A. Ullman, and D.J. Veltkamp, Anal. Chem. 73, 2705-2718 (2001).

46. J. Workman, M.Koch, and D.J. Veltkamp, Anal. Chem. 75, 2859-2876 (2003).

47. N. Dantan and W. Frenzel, Poster No. 80, Proc. ICFIA 2007, Berlin 2007, p 173.

48. J. Ruzicka and E.H. Hansen, Trends Anal. Chem. (in press).

49. J.I. Rhee, Biotechnol. Bioprocess Eng. 12, 289-294 (2007).

50. A. Surribas, O. Cos, J.L. Montesinos, and F. Valero, Biotechnol. Lett. 25, 1795-1800 (2003).

51. S.C. Chung, G.D. Christian, and J. Ruzicka, Process Control Qual. 3, 115-125 (1992).

52. A.M. Pimenta, M.S.C.B.M. Montenegro, A.N. Araujo and J.M. Calatayud, J. Pharm. Biomed. Anal. 40, 16-34 (2006).

53. P.D. Tzanavaras and G.D. Themelis, Anal. Chim. Acta 588, 1-9 (2007).

54. S.A. Motz, J. Klimundova, U.F. Schaefer, S. Balbach, T. Eichinger, P. Solich, and C.-M. Lehr, Anal. Chim. Acta 581, 174-180 (2007).

55. J.-H.Wang and E.H. Hansen, Trends Anal. Chem. 22, 225-231 (2003).

56. Y. Wang, M.-L. Chen, and J.-H. Wang, Appl. Spectrosc. Rev. 42,103-118 (2007).

57. J.-H. Wang and E.H. Hansen, J. Anal. At. Spectrom. 16, 1349-1355 (2001).

58. H. Erxleben and J. Ruzicka, Anal. Chem. 77, 5124-5128 (2005).

59. Y. Ogata, L. Scampavia, J. Ruzicka, C.R. Scott, M.H. Gelb, and F. Turecek, Anal. Chem.74, 4702-4708 (2002).

60. Y. Ogata, L. Scampavia, T.L. Carter, E. Fan, and F. Turecek, Anal. Biochem. 331, 161-168 (2004).

61. X.-B. Long, M. Miró, E.H. Hansen, J.M. Estela, and V. Cerdà, Anal. Chem. 78, 8290-8298 (2006).

62. C.-H. Wu, L. Scampavia, and J. Ruzicka, Analyst 127, 898-905 (2002).

63. C.-H. Wu, L. Scampavia, and J. Ruzicka, Analyst 128, 1123-1130 (2003).

64. J.B. Quintana, M. Miró, J.M. Estela, and V. Cerdà, Anal. Chem. 78, 2832-2840 (2006).

65. J.-H. Wang, E.H. Hansen, and M. Miró, Anal. Chim. Acta 499, 139-147 (2003).

66. M. Miró and E.H. Hansen, Trends Anal. Chem. 25, 267-281 (2006).

67. H. Erxleben and J. Ruzicka, Analyst 130, 469-471 (2005).

68. J. Ruzicka and L. Scampavia, Anal. Chem. 71, 257A-263A (1999). 
69. S. Kradtap-Hartwell, K. Grudpan, and G.D. Christian, Trends Anal. Chem. 23, 619-623 (2004).

70. E.H. Hansen and M. Miró, Appl. Spectrosc. Rev. 43, 1-23 (2008).

71. E.H. Hansen, M. Miró, X.-B. Long, and R. Pedersen, Anal. Lett., 39, 1243-1259 (2006).

72. C.M. Schulz, L. Scampavia, and J. Ruzicka, Analyst 127, 1583-1588 (2002).

73. M. Decuir, I. Lähdesmäki, A.D. Carroll, and J. Ruzicka, Analyst 132, 818-822 (2007).

74. J. Ruzicka, A.D. Carroll, and I. Lähdesmäki, Analyst 131, 799-808 (2006).

75. A.D. Carroll, L. Scampavia, D. Luo, Å. Lernmark, and J. Ruzicka, Analyst 128, 1157-1162 (2003).

76. Y. Gutzman, A.D. Carroll, and J. Ruzicka, Analyst 131, 809-815 (2006).

77. A. Manz, N. Graber, and H.M. Widmer, Sens. Actuators, B 1, 244-248 (1990).

78. E. Dempsey, D. Diamond, M.R. Smyth, G. Urban, G. Jobst, I. Moser, E.M.J. Verpoorte, A. Manz, H.M. Widmer, K. Rabenstein, and R. Freaney, Anal. Chim Acta 346, 341-349 (1997).

79. G.H.W. Sanders and A. Manz, Trends Anal. Chem. 19, 364-378 (2000).

80. N.-T. Nguyen and S. Wereley Fundamental and Applications of Microfluidics; Artech House, Boston, MA, 2002.

81. R.E. Oosterbroek and A. van den Berg, Lab-on-Chip: Miniaturized Systems for Bio(Chemical) Analysis and Synthesis; Elsevier Science, Amsterdam, 2003.

82. B. Kuswandi, B. Nuriman, J. Huskens, and W. Verboom, Anal. Chim. Acta 601, 141-155 (2007).

83. A. van den Berg and P. Bergveld (Eds.) Micro Total Analysis Systems 2000; Proceedings of $\mu$ TAS '2000 Symposium, Enschede, Netherlands; Kluwer Academic Publishers: London, 2000.

84. M. Miró and E.H. Hansen, Anal. Chim. Acta 600, 46-57 (2007).

85. C.-H. Wu and J.L. Liu, PAT--J Process Anal. Technol. 3, 25-30 (2006).

86. C.-H. Wu, L. Scampavia, J. Ruzicka, and B. Zamost, Analyst 126, 291-297 (2001).

87. C.M. Schulz and J. Ruzicka, Analyst 127, 293-1298 (2002).

88. K.A. Edwards and A.J. Baeumner, Anal. Chem. 78, 1958-1966 (2006).

89. J. Ruzicka, Flow Injection Analysis CD-ROM Tutorial, 3rd Ed.; Published by FIAlab Instruments, Inc. (available free of charge at www.flowinjection.com), (2004).

90. X.-W. Chen, J.-H. Wang, and Z.-L. Fang, Talanta 67, 227-232 (2005).

91. X.-W. Chen, W.-X. Wang, and J.-H. Wang, Analyst 130, 1240-1244 (2005).

92. X.-W. Chen, Z.-R. Xu, B.-Y. Qu, Y.-F. Wu, J. Zhou, H.-D. Zhang, Z.-L. Fang, J., and J.-H. Wang, Anal. Bioanal. Chem. 388, 157-163 (2007).

93. X.-W. Chen and J.-H. Wang, Anal. Chim. Acta 602 173-180 (2007).

94. M.D. Luque de Castro, J. Ruiz-Jiménez, and J.A. Pérez-Serradilla, Trends Anal. Chem 27 118-126 (2008). 


\section{Figure legends}

Fig. 1. (a) Flow injection system, where the sample (S) is injected into a carrier stream as propelled by a peristaltic pump (PP), which downstream is merged with reagent(s), the transient signal from the product generated by passing the reaction coil(s) (R) being measured by a suitable detector (D). (b) Sequential injection system as based on using a selection valve, the central communication channel (CC) of which can be programmed to address each of the external ports. Via the central communication line (CL), sample and reagents can by means of the syringe pump be aspirated into the holding coil and afterwards propelled to the detector which monitors the ongoing chemical reaction. (c) Lab-on-valve (LOV) system, the concept of which is a microconduit placed atop a selection valve (as shown in Fig. 5). Ideally containing all means for facilitating the chemical assay, including a flow-through detection cell, the microconduit is also amenable to externally attached components, such as detectors or bead reservoirs for integrating small packed column reactors.

Fig. 2. (a) Simple stopped-flow FI-manifold, where the timer (T) can be set to stop the liquid stream at a preset time. (b) As demonstrated for a spectrophotometric measurement of absorbance, curve (A) shows the signal for continuous pumping, curve (B) for a fast (instantaneous) chemical reaction), while the dashed line $(\mathrm{C})$ indicates the signal output that would be registered if a zeroorder or pseudo-zero-order reaction had taken place within the stop interval. From ref. 14, courtesy John Wiley \& Sons.

Fig. 3. (a) FI-manifold for the detection of glucose with an amperometric sensor to detect enzymatically generated hydrogen peroxide; (b) Calibration graphs for glucose in the concentration range $0-40 \mathrm{mmol} / \mathrm{L}$ at three different flow rates: $(\Delta) 0.50,(\boldsymbol{\Delta}) 0.75$, and $(\mathrm{x}) 1.00 \mathrm{~mL} / \mathrm{min}$. From ref. 28, courtesy Taylor \& Francis.

Fig. 4. Typical course of light generation $(\mathrm{h} v)$ in a bio- or chemiluminescent reaction as a function of time. Quantification can be accomplished either by relating the amount of analyte to the energy released (i.e., integrating the area under the curve), or by using FI and determining the intensity $(\mathrm{dE} / \mathrm{dt})$ after a fixed period of time $(\Delta \mathrm{t})$, which, if pseudo-first reaction conditions are fulfilled $\left(\mathrm{c}_{\mathrm{B}}\right.$ $\left.>>c_{A}\right)$, is directly proportional to the concentration of the analyte $(A)$.

Fig. 5. (a) Close-up of LOV system for bead injection (BI) incorporating two microcolumn positions $\left(\mathrm{C}_{1}\right.$ and $\left.\mathrm{C}_{2}\right)$, along with a diagram of a packed renewable microcolumn (from ref. 55, courtesy Elsevier Science Publishers). (b) Schematic diagram and magnified close-up of an SI-LOV microsystem incorporating a multipurpose flow cell configured for measurement of absorbance. Adapted from ref. 86, courtesy Royal Society of Chemistry.

Fig. 6. (a) Sequence of the stacked zones of sample, reagents and spacer for the determination of ammonia. (b) Stopped-flow readouts as shown in triplicate for different concentrations (0-1200 ppm) of ammonia, revealing the high reproducibility of measurements. The hatched rectangles indicate the stopped-flow measuring periods. From ref. 89, courtesy of the author.

Fig. 7. Experimental setup for bead injection spectroscopy and micro-affinity chromatography. At the bottom is shown in (A) the configuration of the flow cell for capturing and monitoring of beads by UV-Vis spectrophotometry; and in (B) the configuration of the flow cell for micro-affinity chromatography. The beads are retained as a microcolumn by a sheath of optical fiber, designed to 
allow the mobile phase to pass freely into the flow cell (light path $10 \mathrm{~mm}$ ). From ref. 89, courtesy of the author.

Fig. 8. LOV system employed for DNA separation and purification from human blood, integrating a demountable fluorescence flow cell. EB, ethidium bromide; LIF, laser-induced fluorescence; P1 and $\mathrm{P} 2$, peristaltic pumps; $\mathrm{SP}$, syringe pump; $\mathrm{V}_{1}$, three-way valve; and $\mathrm{C}_{1}$ and $\mathrm{C}_{2}$, micro columns. From ref. 92, courtesy of Springer Science and Business Media. 
(a)

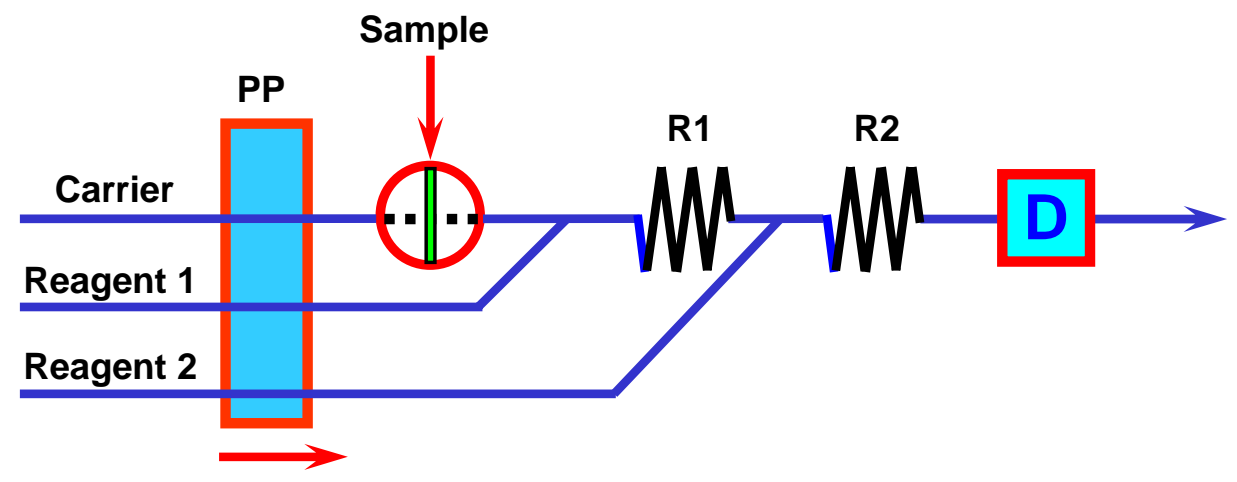

(b)

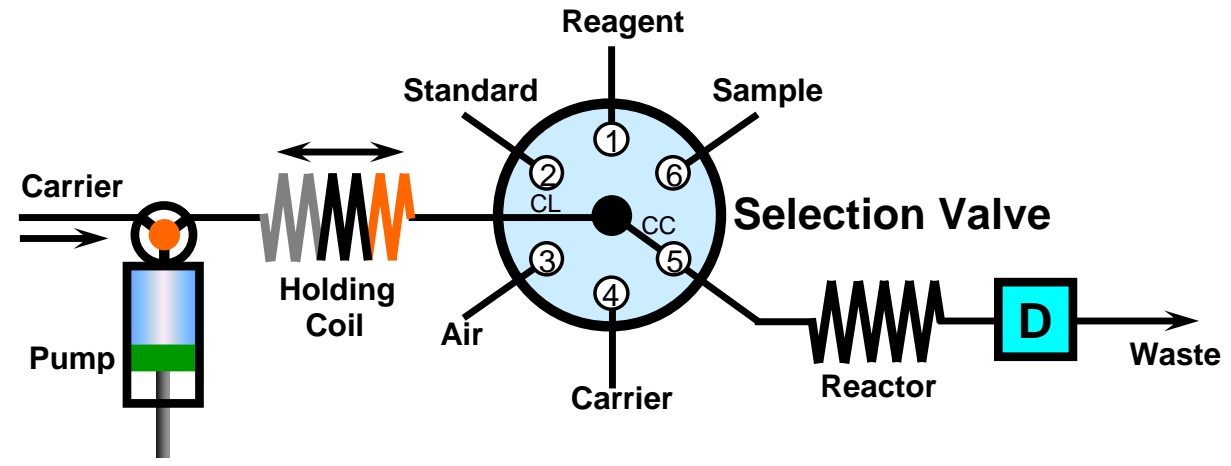

(c)

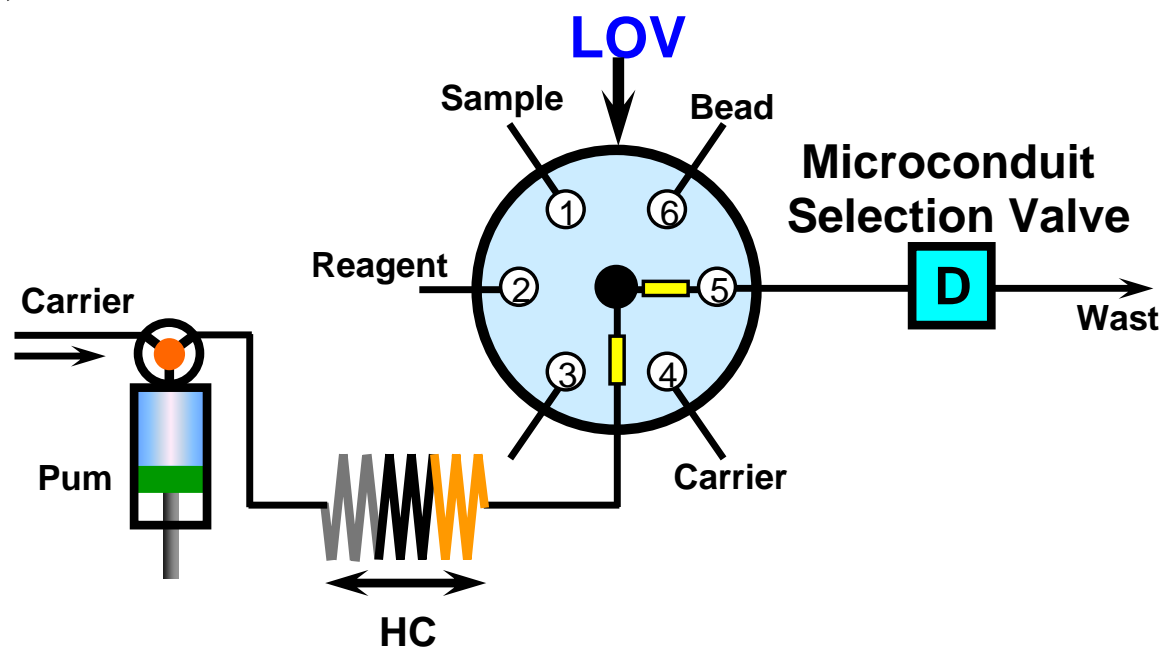

Fig. 1 


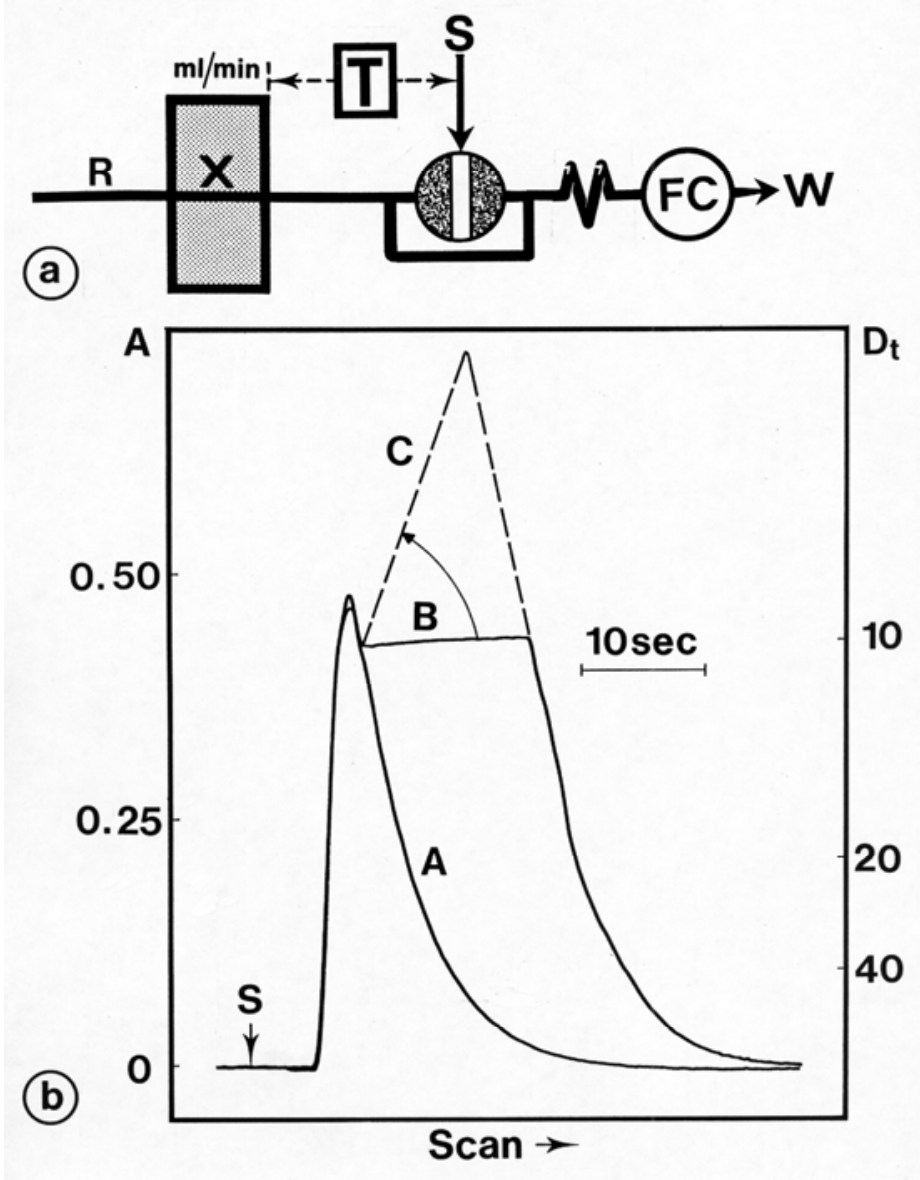

Fig. 2 

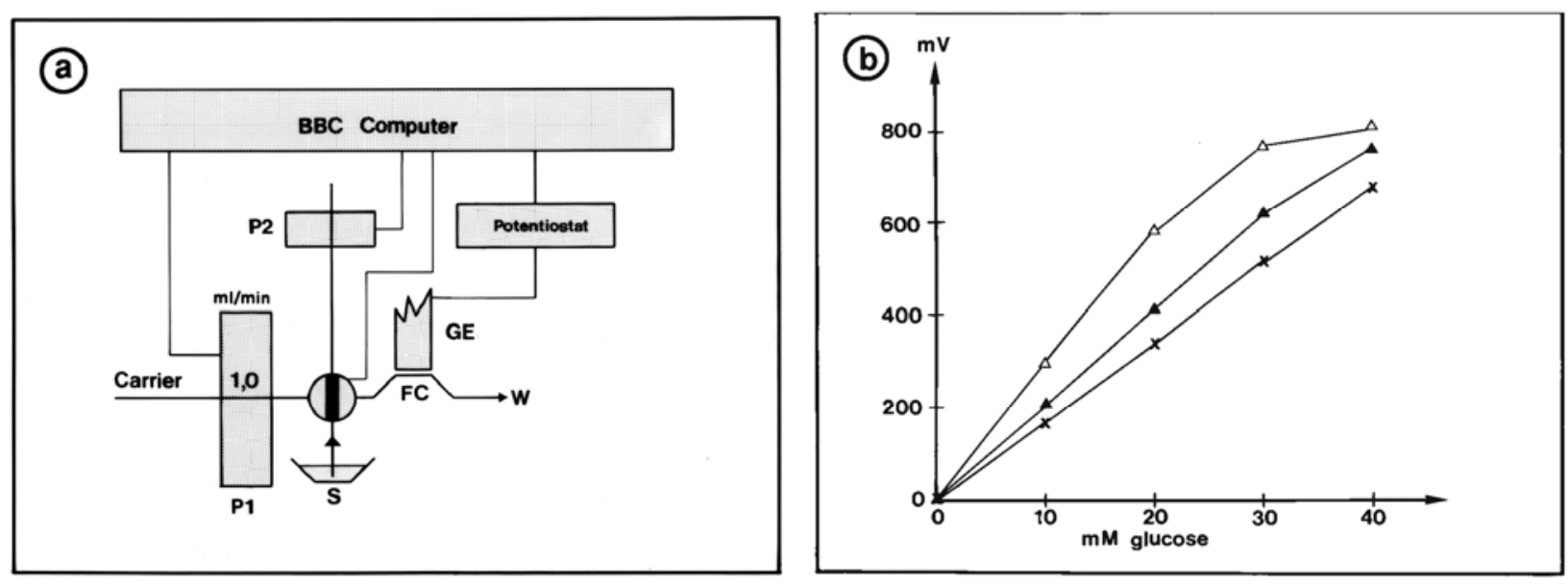

Fig. 3 


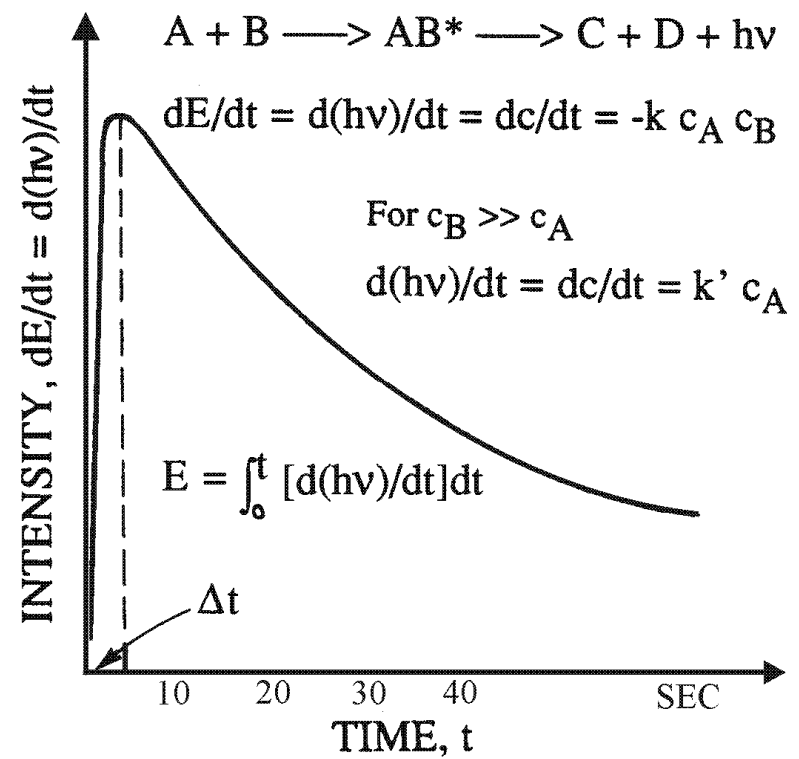

Fig. 4 


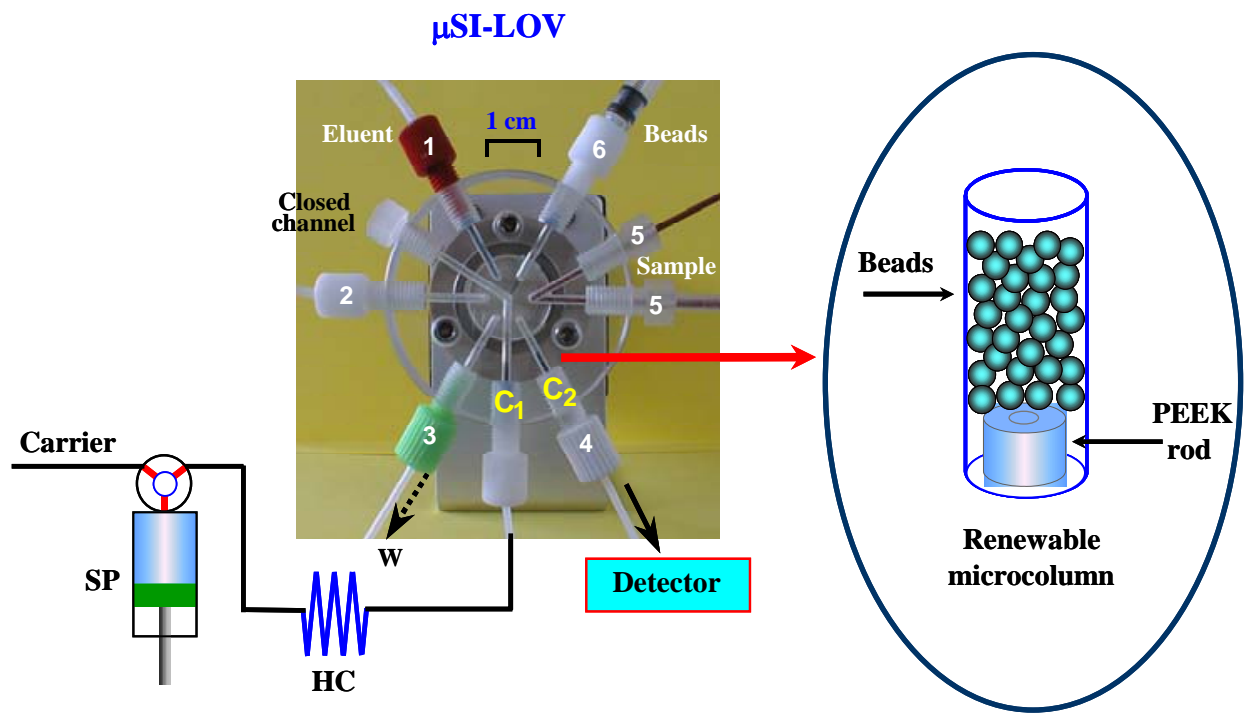

Fig. 5a 


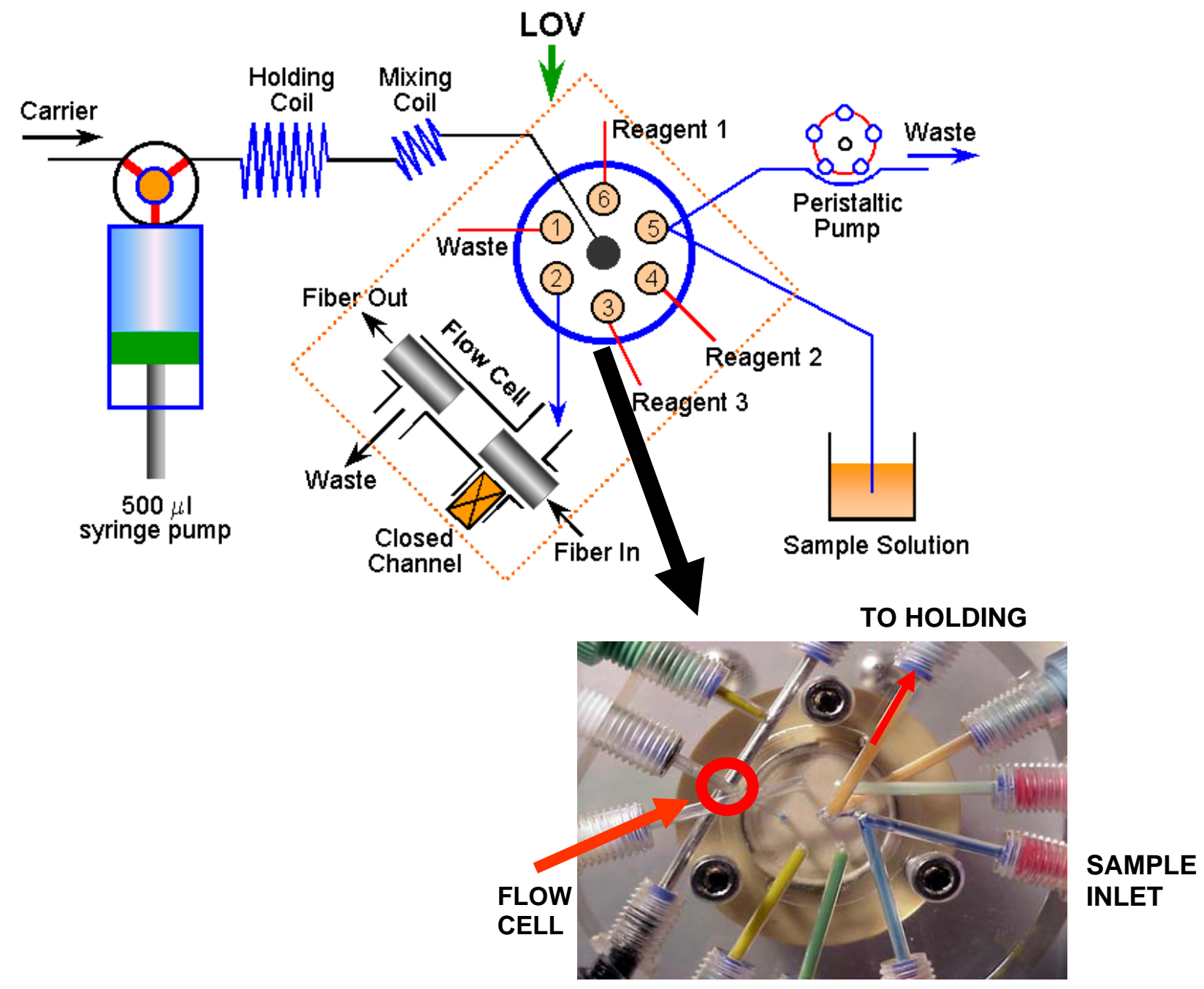

Fig. 5b 


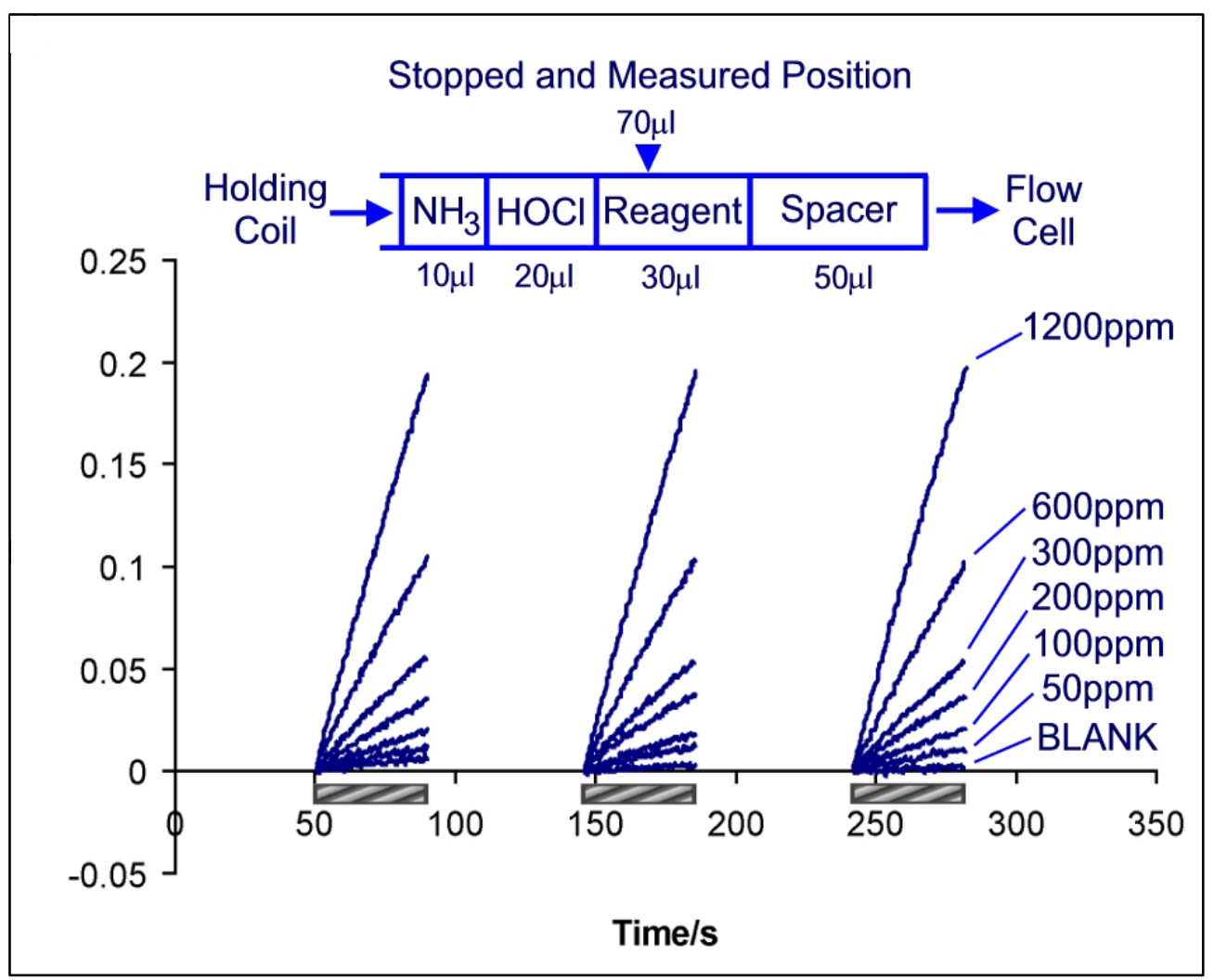

Fig. 6 

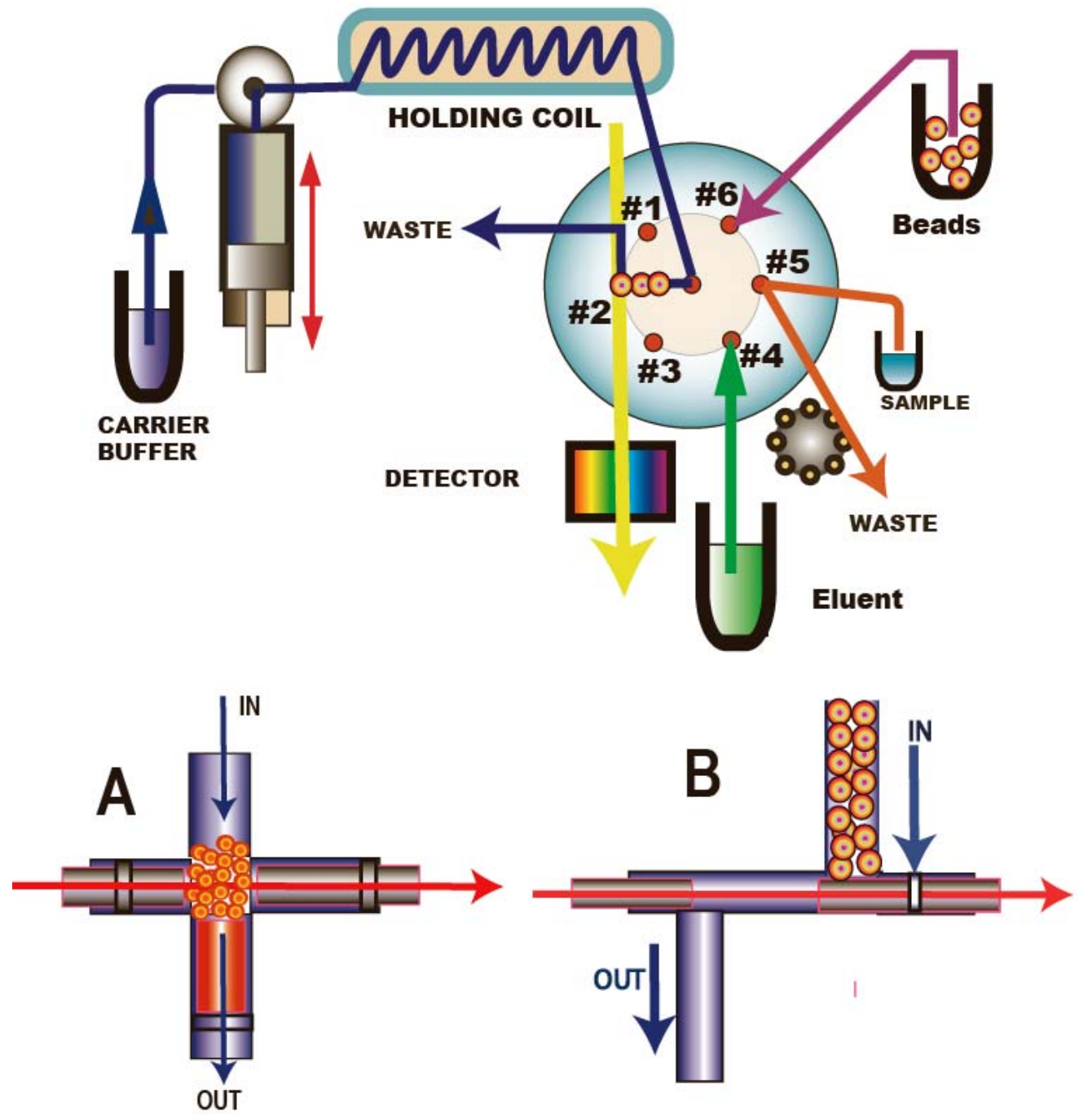

Fig. 7 


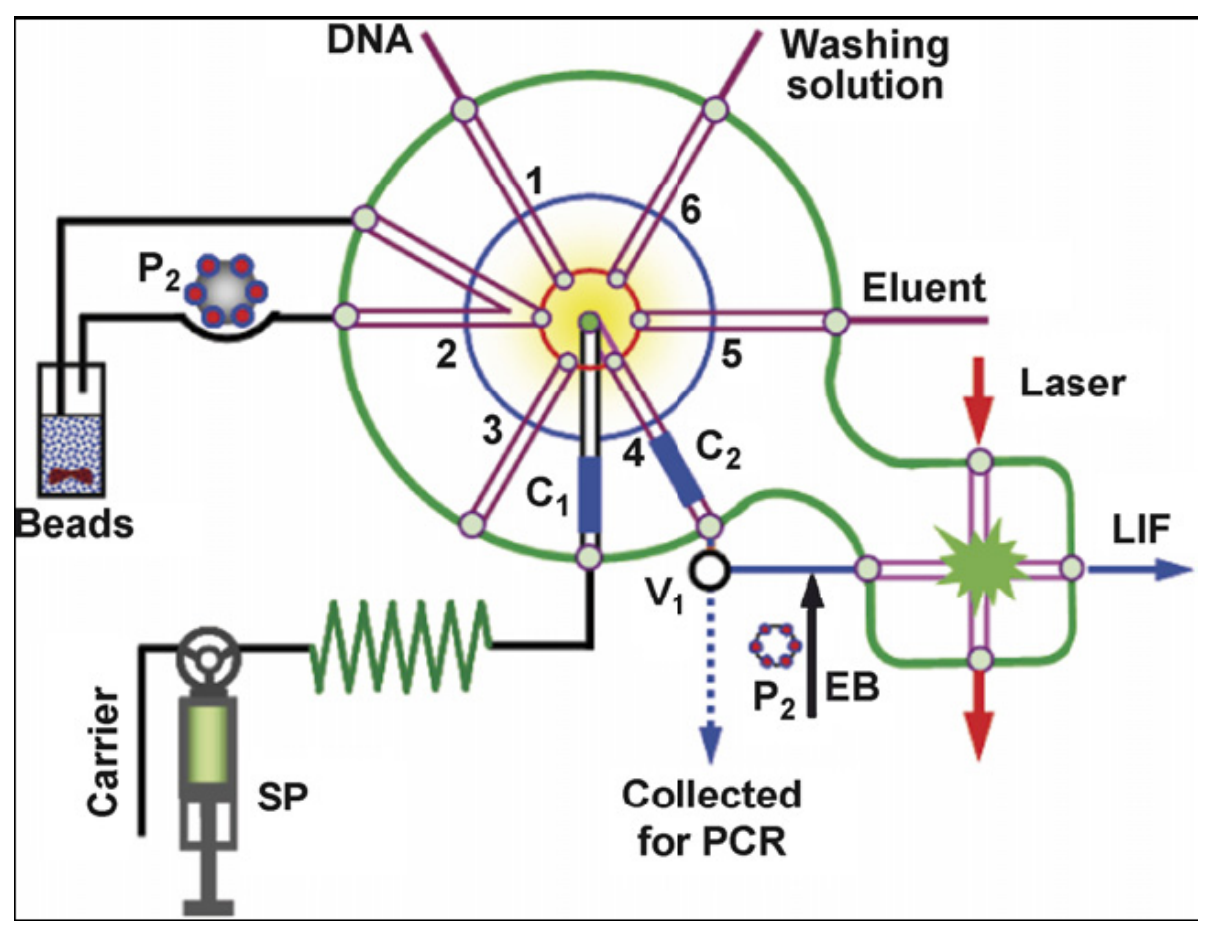

Fig. 8 
Table 1. Examples of FIA gradient techniques

\section{Gradient dilution}

Selecting and using for the analytical readout specific fluid elements along the concentration gradient, the concentration being $C=C^{\mathrm{o}} / D\left(t_{\mathrm{i}}\right)$. To be used, for instance, to accommodate the concentration of sample to the dynamic range of a detector.

\section{Gradient calibration}

Identifying and exploiting a number of elements along the gradient, the concentrations of which are given through the dispersion coefficient of the individual elements. A multipoint calibration curve can be obtained from a single injection of a concentrated sample.

\section{Gradient scanning}

Combining the use of gradient dilution with the use of a dynamic detector which, for each concentration level, is able continuously to scan a physical parameter, such as wavelength or potential.

\section{Stopped-flow}

Increase of sensitivity of measurement by increasing residence time, or quantifying sample concentration by measuring a reaction rate under pseudo-zero-order reaction conditions (see Fig. 2).

\section{Titration}

Identifying elements of fluids on the ascending and descending parts of the concentration gradient where equivalence between titrand and titrant is obtained, and relating the time difference between these elements to the concentration of injected analyte.

\section{Penetrating zones}

Exploitation of the response curves from the concentration gradients formed when two or more zones are injected simultaneously. In addition to acting as an economical way of introducing sample and reagent solutions, it can be used for measuring selectivity coefficients, and to make standard addition over a wide, controllable range of standard/analyte concentration ratios. 
Table 2. Analytical performance of selected flow methods involving enzymic reactions for monitoring fermentation and culture broths

\begin{tabular}{|c|c|c|c|c|c|c|c|}
\hline Analyte(s) & Microorganism & $\begin{array}{c}\text { Flow } \\
\text { approach }\end{array}$ & $\begin{array}{l}\text { Detection } \\
\text { technique }\end{array}$ & Linear range & Detection limit & $\begin{array}{l}\text { Precision } \\
(\mathrm{RSD}, \%)\end{array}$ & Reference \\
\hline $\begin{array}{l}\text { Glucose and } \\
\text { ammonia }\end{array}$ & $\begin{array}{l}\text { Penicillium } \\
\text { chrysogenum }\end{array}$ & FI & $\begin{array}{c}\text { SP } \\
\text { (ammonium) } \\
\text { CL (glucose) }\end{array}$ & $\begin{array}{l}\text { 5-700 mg L } \\
\quad \text { (glucose) }^{-1} \\
0-10.8 \mathrm{mg} \mathrm{L}^{-1} \\
\text { (ammonium) }\end{array}$ & $\begin{array}{c}5 \mathrm{mg} \mathrm{L}^{-1} \\
\text { (glucose) } \\
\mathrm{NR} \text { (ammonium) }\end{array}$ & $\begin{array}{c}<2(\text { glucose }) \\
\text { NR } \\
\text { (ammonium) }\end{array}$ & 10 \\
\hline $\begin{array}{c}\text { Glucose and } \\
\text { ethanol }\end{array}$ & NR & SI & Amp & $\begin{array}{l}5-750 \mathrm{mg} \mathrm{L}^{-1} \\
\quad \text { (glucose) } \\
0.15-30 \mathrm{mg} \mathrm{L}^{-1} \\
\quad \text { (ethanol) }\end{array}$ & $15 \mu \mathrm{g} \mathrm{L}^{-1}\left(\mathrm{H}_{2} \mathrm{O}_{2}\right)$ & $\begin{array}{l}<1.2(\text { glucose }) \\
<2.2(\text { ethanol })\end{array}$ & 12 \\
\hline Ethanol & $\begin{array}{l}\text { Saccharomyces } \\
\text { cerevisiae }\end{array}$ & $\mathrm{FI} / \mathrm{SI}$ & Amp & $0.05-11.5 \mathrm{mg} \mathrm{L}^{-1}$ & $50 \mu \mathrm{g} \mathrm{L}^{-1}$ & 7.4 & 22 \\
\hline $\begin{array}{l}\text { Glucose and L- } \\
\text { lactate }\end{array}$ & $\begin{array}{l}\text { Lactobacillus } \\
\text { casei }\end{array}$ & FI & Amp & $\begin{array}{c}2-100 \mathrm{~g} \mathrm{~L}^{-1} \\
\text { (glucose) } \\
1-60 \mathrm{~g} \mathrm{~L}^{-1} \text { (lactate) }\end{array}$ & $\begin{array}{c}2 \mathrm{~g} \mathrm{~L}^{-1} \text { (glucose) } \\
1 \mathrm{~g} \mathrm{~L}^{-1} \text { (lactate) }\end{array}$ & NR & 23 \\
\hline Lactic acid & $\begin{array}{l}\text { Mammalian cell } \\
\text { 293S (kidney) }\end{array}$ & FI & Amp & $0-0.27 \mathrm{~g} \mathrm{~L}^{-1}$ & $4.5 \mathrm{mg} \mathrm{L}^{-1}$ & 1.5 & 24 \\
\hline $\begin{array}{l}\text { Glucose and L- } \\
\text { lactate }\end{array}$ & $\begin{array}{l}\text { Lactococcus } \\
\text { lactis }\end{array}$ & FI & Amp & $\begin{array}{l}0.01-0.1 \mathrm{~g} \mathrm{~L}^{-1} \\
\quad \text { (glucose) } \\
0.01-0.5 \mathrm{~g} \mathrm{~L}^{-1} \\
\quad \text { (lactate) }\end{array}$ & $\begin{array}{c}10 \mathrm{mg} \mathrm{L}^{-1} \\
\text { (glucose and } \\
\text { lactate) }\end{array}$ & NR & 25 \\
\hline $\begin{array}{l}\text { Glucose, } \\
\text { ethanol and } \\
\text { glutamate }\end{array}$ & $\begin{array}{l}\text { Torulopsis } \\
\text { versatilis }\end{array}$ & FI & Amp & $\begin{array}{c}5-50 \mathrm{~g} \mathrm{~L}^{-1} \text { (glucose } \\
\text { and ethanol) } \\
1-20 \mathrm{~g} \mathrm{~L}^{-1} \\
\text { (glutamate) }\end{array}$ & $\begin{array}{c}5 \mathrm{~g} \mathrm{~L}^{-1} \text { (glucose } \\
\text { and ethanol) } \\
1 \mathrm{~g} \mathrm{~L}^{-1} \\
\text { (glutamate) }\end{array}$ & NR & 33 \\
\hline
\end{tabular}




\begin{tabular}{|c|c|c|c|c|c|c|c|}
\hline Analyte(s) & Microorganism & $\begin{array}{c}\text { Flow } \\
\text { approach }\end{array}$ & $\begin{array}{l}\text { Detection } \\
\text { technique }\end{array}$ & Linear range & Detection limit & $\begin{array}{l}\text { Precision } \\
(\mathrm{RSD}, \%)\end{array}$ & Reference \\
\hline $\begin{array}{c}\text { Glutamine } \\
\text { and glutamate }\end{array}$ & $\begin{array}{l}\text { Mammalian cell } \\
\text { culture }\end{array}$ & FI & $\mathrm{SP}$ & $\begin{array}{l}0-0.44 \mathrm{~g} \mathrm{~L}^{-1} \\
\text { (glutamate) } \\
0-1.0 \mathrm{~g} \mathrm{~L}^{-1} \\
\text { (glutamine) }\end{array}$ & NR & $\begin{array}{l}<1 \text { (glutamate } \\
\text { and glutamine) }\end{array}$ & 34 \\
\hline Glucose & $\begin{array}{c}\text { Animal cells } \\
\text { (Langerhans islets), } \\
\text { Escherichia coli and } \\
\text { Saccharomyces } \\
\text { cerevisiae }\end{array}$ & FI & Amp & $0-1.1 \mathrm{~g} \mathrm{~L}^{-1}$ & $10 \mathrm{mg} \mathrm{L}^{-1}$ & 1 & 35 \\
\hline $\begin{array}{l}\text { Glucose, } \\
\text { lactic acid, } \\
\text { penicillin }\end{array}$ & $\begin{array}{l}\text { Penicillium } \\
\text { chrysogenum }\end{array}$ & SI & $\mathrm{CL}$ & $\begin{array}{c}0-100 \mathrm{mg} \mathrm{L}^{-1} \\
\text { (glucose, penicillin } \\
\text { and lactic acid) }\end{array}$ & $\begin{array}{c}5 \mathrm{mg} \mathrm{L}^{-1} \text { (glucose } \\
\text { and lactic acid) } \\
10 \mathrm{mg} \mathrm{L}^{-1} \\
\text { (penicillin) }\end{array}$ & $\begin{array}{c}2.06 \text { (glucose) } \\
2.56 \text { (lactic } \\
\text { acid) } \\
<2 \text { (penicillin) }\end{array}$ & 37 \\
\hline $\begin{array}{c}\text { Glucose, } \\
\text { lactate, } \\
\text { ethanol, } \\
\text { galactose, L- } \\
\text { aminoacids }\end{array}$ & $\begin{array}{l}\text { Mesenchymal stem } \\
\text { cells, Escherichia } \\
\text { coli and } \\
\text { Saccharomyces } \\
\text { cerevisiae }\end{array}$ & FI & SP & $\begin{array}{c}0-1.5 \mathrm{~g} \mathrm{~L}^{-1} \\
\text { (glucose) } \\
0-1.2 \mathrm{~g} \mathrm{~L}^{-1} \\
\text { (ethanol) } \\
0-0.42 \mathrm{~g} \mathrm{~L}^{-1} \\
\text { (lactate) } \\
0-5 \mathrm{~g} \mathrm{~L}^{-1} \text { (L- } \\
\text { leucine) }\end{array}$ & $\begin{array}{c}11 \mathrm{mg} \mathrm{L}^{-1} \\
\text { (glucose) } \\
16 \mathrm{mg} \mathrm{L}^{-1} \\
\text { (ethanol) } \\
5 \mathrm{mg} \mathrm{L}^{-1} \text { (lactate } \\
\text { and L-leucine) }\end{array}$ & $<1$ & 39 \\
\hline D-lactic acid & $\begin{array}{c}\text { Lactobacillus } \\
\text { delbrueckii }\end{array}$ & SI & SP & $0.18-2.25 \mathrm{~g} \mathrm{~L}^{-1}$ & $90 \mathrm{mg} \mathrm{L}^{-1}$ & NR & 40 \\
\hline
\end{tabular}




\begin{tabular}{|c|c|c|c|c|c|c|c|}
\hline Analyte(s) & Microorganism & $\begin{array}{c}\text { Flow } \\
\text { approach }\end{array}$ & $\begin{array}{l}\text { Detection } \\
\text { technique }\end{array}$ & Linear range & Detection limit & $\begin{array}{l}\text { Precision } \\
(\mathrm{RSD}, \%)\end{array}$ & Reference \\
\hline $\begin{array}{c}\text { Glucose, } \\
\text { lactose, } \\
\text { galactose, lactic } \\
\text { acid }\end{array}$ & $\begin{array}{l}\text { Streptococcus } \\
\text { cremoris }\end{array}$ & FI & CL & 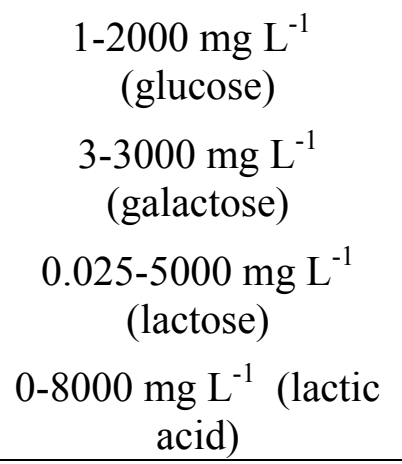 & $\begin{array}{c}5 \mathrm{mg} \mathrm{L}^{-1} \text { (glucose) } \\
3 \mathrm{mg} \mathrm{L}^{-1} \\
\text { (galactose) } \\
0.1 \mathrm{mg} \mathrm{L}^{-1} \text { (lactose) } \\
0.1 \mathrm{mg} \mathrm{L}^{-1} \text { (lactic } \\
\text { acid) }\end{array}$ & $\begin{array}{l}\leq 1 \text { (glucose, } \\
\text { galactose, and } \\
\text { lactose) } \\
2 \text { (lactic acid) }\end{array}$ & 41 \\
\hline Methanol & Pichia pastoris & SI & SP & $0-2 \mathrm{~g} \mathrm{~L}^{-1}$ & $0.12 \mathrm{~g} \mathrm{~L}^{-1}$ & $<4$ & 50 \\
\hline $\begin{array}{l}\text { Ammonium, } \\
\text { glucose, } \\
\text { glycerol and } \\
\text { free iron }\end{array}$ & $\begin{array}{l}\text { Escherichia } \\
\text { coli }\end{array}$ & LOV & SP & 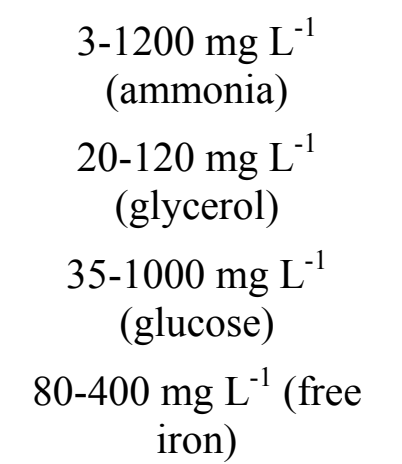 & $\begin{array}{c}3 \mathrm{mg} \mathrm{L}^{-1} \\
\text { (ammonia) } \\
20 \mathrm{mg} \mathrm{L}^{-1} \\
\text { (glycerol) } \\
35 \mathrm{mg} \mathrm{L}^{-1} \text { (glucose) } \\
80 \mathrm{mg} \mathrm{L}^{-1} \text { (free } \\
\text { iron) }\end{array}$ & $\begin{array}{c}0.9 \text { (ammonia) } \\
1.1 \text { (glycerol } \\
\text { and glucose) } \\
1.5 \text { (free iron) }\end{array}$ & 86 \\
\hline
\end{tabular}

Abbreviations: FI, Flow Injection; SI, Sequential Injection; LOV, Lab-on-a-Valve; SP, Spectrophotometry; Amp, Amperometry; CL, Chemiluminescence; RSD, Relative standard deviation; NR: Not reported. 
